Florida International University

FIU Digital Commons

FIU Electronic Theses and Dissertations

University Graduate School

6-2-2015

\title{
The Influence of Parental Aggression and Cultural Gender Role Beliefs on Hispanic College Women's Experiences with Psychological Aggression
}

Laura A. Oramas

Florida International University, loram001@fiu.edu

DOI: 10.25148 /etd.FIDC000089

Follow this and additional works at: https:// digitalcommons.fiu.edu/etd

Part of the Domestic and Intimate Partner Violence Commons, Multicultural Psychology Commons, and the Social Psychology Commons

\section{Recommended Citation}

Oramas, Laura A., "The Influence of Parental Aggression and Cultural Gender Role Beliefs on Hispanic College Women's Experiences with Psychological Aggression" (2015). FIU Electronic Theses and Dissertations. 2210.

https://digitalcommons.fiu.edu/etd/2210 


\section{FLORIDA INTERNATIONAL UNIVERSITY \\ Miami, Florida}

THE INFLUENCE OF PARENTAL AGGRESSION AND CULTURAL GENDER

ROLE BELIEFS ON HISPANIC COLLEGE WOMEN'S EXPERIENCES WITH

PSYCHOLOGICAL AGGRESSION

A dissertation submitted in partial fulfillment of the

requirements for the degree of

DOCTOR OF PHILOSOPHY

in

PSYCHOLOGY

by

Laura A. Oramas

2015 
To: Dean Michael R. Heithaus

College of Arts and Sciences

This dissertation, written by Laura A. Oramas, and entitled The Influence of Parental Aggression and Cultural Gender Role Beliefs on Hispanic College Women's Experiences with Psychological Aggression, having been approved in respect to style and intellectual content, is referred to you for judgment.

We have read this dissertation and recommend that it be approved.

\begin{tabular}{rr}
\hline Asia Eaton \\
\hline Leslie Frazier \\
\hline Maureen Kenny \\
\hline Dionne Stephens, Major Professor
\end{tabular}

Date of Defense: June 2, 2015

The dissertation of Laura A. Oramas is approved.

Dean Michael R. Heithaus College of Arts and Sciences

Dean Lakshmi N. Reddi University Graduate School

Florida International University, 2015 


\section{DEDICATION}

This dissertation is dedicated to my sister, Sara Oramas, who is currently considering following in my footsteps. While I may not have made the journey to a $\mathrm{Ph} . \mathrm{D}$. look easy, I hope you never allow anything or anyone discourage you from pursuing your dreams. 


\section{ACKNOWLEDGMENTS}

I would like to extend my sincerest gratitude to my family and committee members, without whom this dissertation would not have been possible.

First and foremost, I would like to thank my major professor and mentor, Dr.

Dionne Stephens, for her patience and guidance throughout the process of this dissertation. I am tremendously grateful for the support that she has consistently provided to me throughout the process of this research project and the completion of this dissertation. I would also like to thank my committee members, Drs. Asia Eaton, Maureen Kenny, and Leslie Frazier for believing in my research and for their contributions to the development of the final product.

I would like to thank my parents, Bette and Alex Oramas, who always instilled in me the importance and value of education. I am forever grateful for their commitment to ensuring that my siblings and I have had every possible door open to us, and for never letting us forget there was nothing we could not accomplish.

Finally, I would like to thank Dr. E. George Simms and the Ronald E. McNair Postbaccalaureate Achievement Program for their support and assistance in both preparing me and helping me to gain admission into graduate school, as well as for providing financial assistance so that I could complete the final stage of this dissertation. 


\author{
ABSTRACT OF THE DISSERTATION \\ THE INFLUENCE OF PARENTAL AGGRESSION AND CULTURAL GENDER \\ ROLE BELIEFS ON HISPANIC COLLEGE WOMEN'S EXPERIENCES WITH \\ PSYCHOLOGICAL AGGRESSION \\ by
}

Laura A. Oramas

Florida International University, 2015

Miami, Florida

Professor Dionne Stephens, Major Professor

Psychological aggression is present in as many as $89-97 \%$ of college women's intimate relationships (Cercone, Beach, \& Arias, 2005; Riggs \& O’Leary, 1996).

Victimization has been linked to negative physical and mental health consequences including depression, anxiety, and chronic pain (Coker, Smith, Bethea, King, \& McKeown, 2000; Derrick, Testa, \& Leonard, 2014; Pico-Alfonso et al., 2006). Psychological aggression also serves as a risk factor for future or continued physical intimate partner violence (Centers for Disease Control and Prevention [CDC], 2014), which can result in bruises, broken bones, or in extreme cases, even death. Parental modeling of appropriate relationship behaviors may be an important factor in young adult women's learning how to behave in their own intimate relationships. Studies have produced mixed results when assessing the role of engendered cultural influences on this phenomenon, with many reporting that women holding traditional gender role beliefs are at an increased risk for experiencing relationship aggression (Brownridge, 2002; CDC, 2014; Eaton \& Matamala, 2014; Fitzpatrick, Salgado, Suvak, King, \& King, 2004). The 
current dissertation seeks to investigate the roles of traditional, culturally informed gender role beliefs in the intergenerational modeling of psychological aggression in Hispanic college women's intimate relationships. A total of 687 students from a large Hispanic Serving Institution (HSI) in the southeastern United States participated in this study. The results of Study 1 showed that parental use of psychological aggression and participants' beliefs consistent with caballerismo influenced Hispanic college women's victimization in their intimate relationships. The results of Study 2 indicated that parental use of psychological aggression, participants' beliefs consistent with marianismo, and participants' beliefs sanctioning their own use of psychological aggression toward their boyfriends significantly influenced Hispanic college women's perpetration of this type of aggression in their intimate relationships. The findings from this dissertation are important as few studies have examined intimate partner violence or conflict strategies in Hispanic college populations, despite the fact that they constitute the largest group of ethnic minority women on campuses today (Fry, 2011). Further, they contribute to our ability to effectively critique traditional gender beliefs used to examine Hispanic women's behavioral and psychological outcomes. 


\section{TABLE OF CONTENTS}

CHAPTER PAGE

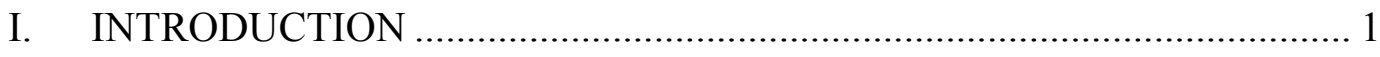

II. LITERATURE REVIEW ................................................................... 7

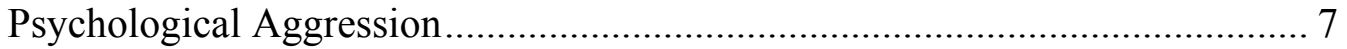

Theories of Intimate Partner Violence ........................................................... 10

Parental Influence ............................................................................. 15

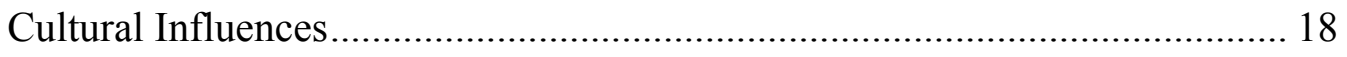

Attitudes Toward and Support of IPV .................................................... 24

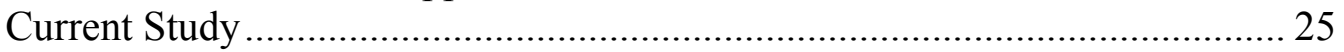

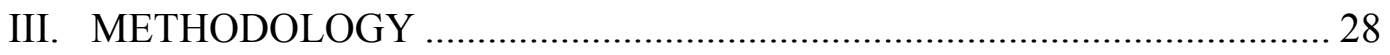

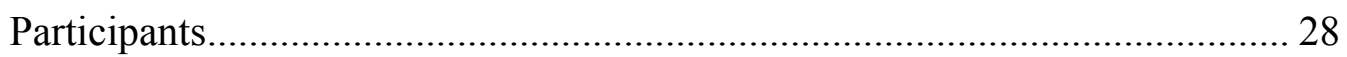

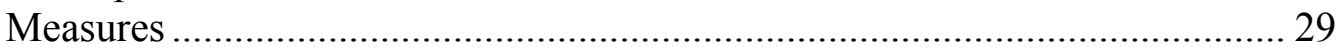

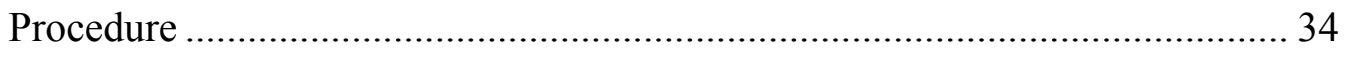

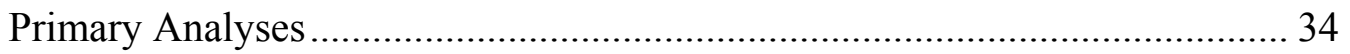

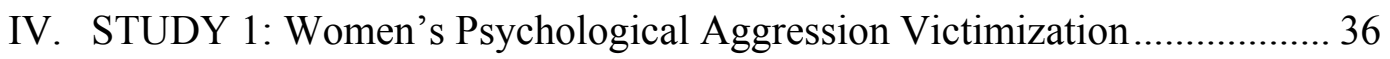

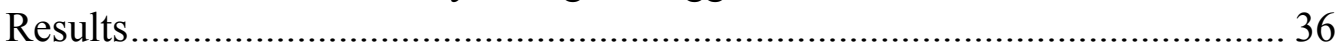

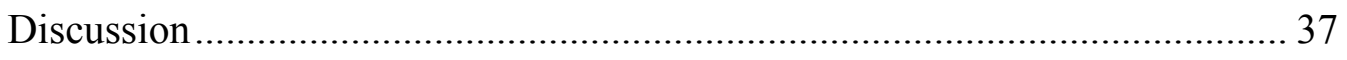

V. STUDY 2: Women's Perpetration of Psychological Aggression ................ 43

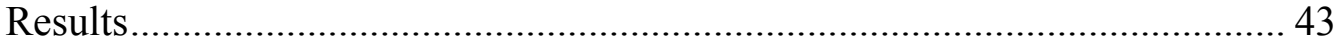

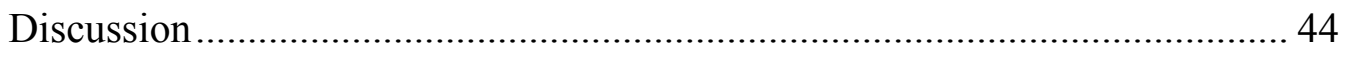

VI. GENERAL DISCUSSION ........................................................... 47

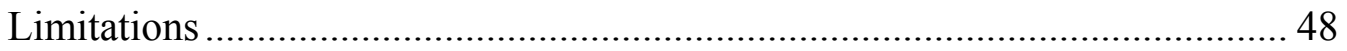

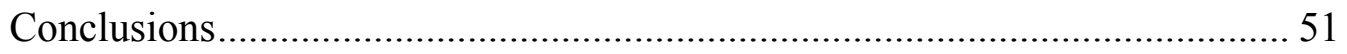

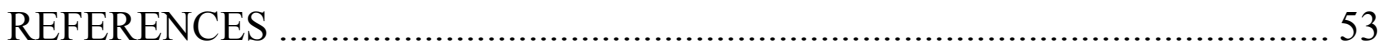

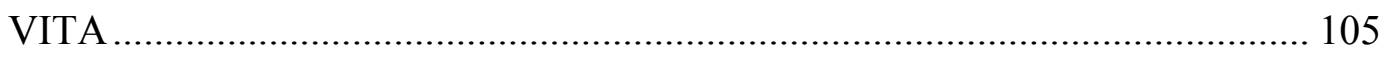




\section{LIST OF TABLES}

TABLE

PAGE

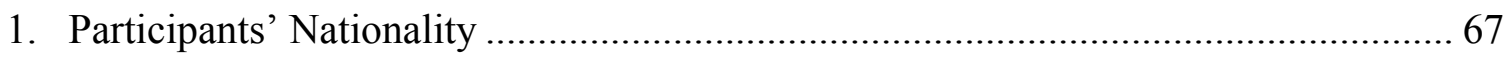

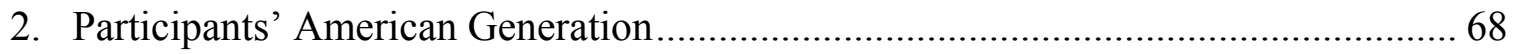

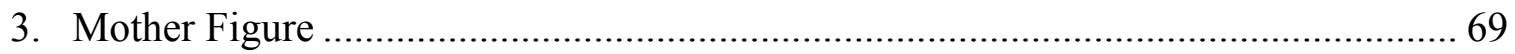

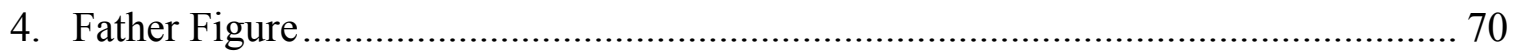

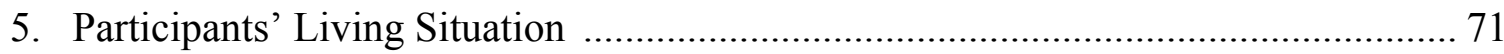

6. Mothers' Highest Level of Education Achieved ………............................................. 72

7. Fathers' Highest Level of Education Achieved ............................................................ 73

8. Participant's Class Level (Based on Number of Credits Obtained) ........................... 74

9. Participant's Relationship Status at the Time of Survey Completion.......................... 75

10. Participant's Number of Past-Year Relationships ................................................. 76

11. Study 1 Intercorrelation of Variables...................................................................... 77

12. Study 2 Intercorrelation of Variables.................................................................... 78

13. Study 1 Tolerance Levels and Variance Inflation Factors (VIF)............................... 79

14. Study 2 Tolerance Levels and Variance Inflation Factors (VIF)............................... 80

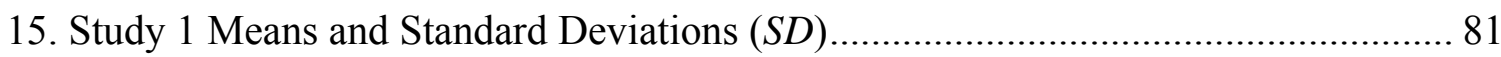

16. Intimate Partner Violence Attitudes Scale: Abuse Subscale (Victimization)............. 82

17. Machismo Scale (Questions Assessing Machismo Beliefs) ......................................... 83

18. Machismo Scale (Questions Assessing Caballerismo Beliefs)................................... 86

19. Conflict Tactics Scale 2 (Mother's Use of Psychological Aggression toward

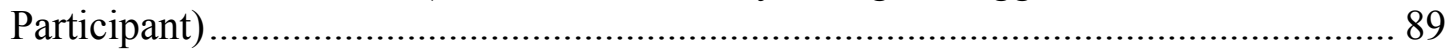

20. Conflict Tactics Scale 2 (Father's Use of Psychological Aggression toward Participant)

21. Conflict Tactics Scale 2 (Boyfriend's Use of Psychological Aggression toward Participant) 


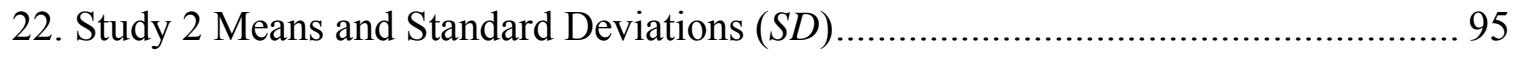

23. Intimate Partner Violence Attitudes Scale: Abuse Subscale (Perpetration) .............. 96

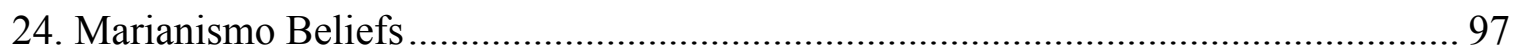

25. Conflict Tactics Scale 2 (Participant's Use of Psychological Aggression toward

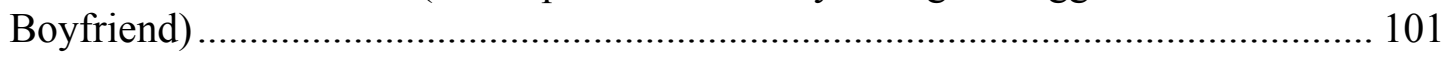




\section{INTRODUCTION}

There is large body of research on college students' intimate relationships as this phase of the lifespan represents a critical period in the development of an individual's identity. For many college students entering intimate relationships, this is the first time that they are able to make independent decisions about their sexual health and relationships. Making these independent decisions requires them to draw upon values, beliefs and practices utilized within familial contexts to make independent decisions about and within relationships for the first time in their lives. Given the significance of intimate relationships during college, much of the research has focused on various forms of intimate partner violence (IPV) and its relevance to familial socialization processes and gender role beliefs in college students (Black, Sussman, \& Unger, 2010; Fitzpatrick, et al., 2004; Hines \& Saudino, 2002; Nabors \& Jasinski, 2009; Skuja \& Halford, 2004). These findings highlight the importance of understanding familial socialization and identity development and their relationship to college women's conflict negotiation in intimate relationships (Black et al., 2010; Fitzpatrick, et al., 2004).

Interestingly, research over the past decade has become more focused in its investigation of IPV due to the recognition that a) there are variations in the types of violence that occurs; and b) the rates of occurrence differ across populations and contexts (e.g., college versus community). When considering variations in types of violence, one area gaining increased attention is psychological aggression, particularly within college populations. Psychological aggression includes behaviors, threats, or coercive tactics which cause trauma to the recipient (CDC, 2014). Examples of psychological aggression include controlling what the victim can and cannot do, embarrassing the victim, isolating 
the victim from friends and family, and denying the victim access to financial resources (CDC, 2014).

Research has shown that it is important to distinguish between psychological aggression and other forms of IPV, as each type of violence is used differently across contexts and populations. For example, although it is estimated that $39 \%$ of college students experience some form of physical violence, an estimated $88 \%$ have experienced some form of verbal aggression in their dating relationships (Alleyne-Green, ColemanCowger, \& Henry, 2012; Katz, Washington, Kuffel, \& Brown, 2006; Muñoz-Rivas, Graña, O'Leary, \& González, 2009; Nabors \& Jasinski, 2009; Prospero \& Vohra-Gupta, 2007; Schnurr, Mahatmya, \& Basche, 2013; White \& Koss, 1991). This is concerning given that psychological aggression can have serious psychological and physical consequences to victims, including physical symptomology such as chronic pain (Coker et al., 2000) and psychological symptomology such as depression and anxiety (Hegarty et al., 2004; Pico-Alfonso et al., 2006). Further, psychological aggression is one of the key contributors to the use of physical intimate partner violence tactics in young adult and adult relationships (CDC, 2014). Thus, psychological aggression victimization also increases a woman's risk for experiencing physical aggression within intimate relationships, which can result in bruises, broken bones, or even death (CDC, 2014).

There is a clear need to examine college women's psychological aggression perpetration and victimization given that their rates of usage have been found to be very similar to men's experiences. Indeed, research over the past two decades has consistently shown that women tend to be more likely than men to use this tactic in conflict with significant others, increasing the likelihood of male victimization (Harned, 2001; Hines 
\& Saudino, 2003; Lohman, Neppl, Senia, \& Schofield, 2013; Schnurr et al., 2013; Stockdale, Tackett, \& Coyne, 2013). Recent studies have consistently shown that women use psychological aggression more than any other aggressive tactic in their intimate relationships (Dowd, Leisring \& Rosenbaum, 2005; Harned, 2001; Straus \& Sweet, 1992), with as many as $86 \%$ of heterosexual college women have reported perpetrating psychological aggression in their intimate relationships on at least one occasion (Hines \& Saudino, 2003).

While alarming, these rates of psychological aggression perpetration by women must be contextualized with the understanding that responses to violence are engendered (Brownridge, 2002; Fitzpatrick et al., 2004). Specifically, the reciprocal nature of IPV has been identified as influencing the degree to which and reasons why women use psychological aggression (Atkin, Smith, Roberto, Fediuk, \& Wagner, 2002; Capaldi, Kim, \& Shortt, 2007; Infante, Sabourin, Rudd, \& Shannon, 1990; Murphy \& Blumenthal, 2000). Researchers note that women often use psychological aggression when responding to their partners' use of IPV. Psychological aggression is particularly common among women because it is one of the few forms of IPV which does not require great physical strength to perpetrate. Thus, because women may be physically weaker than their male counterparts, it stands to reason that they would seek out conflict tactics which they can easily carry out (e.g., belittling them, swearing, slamming doors, breaking things; see Bjorkqvist, 1994). Added to this is the fact that psychological aggression is a less "obvious" form of IPV in that it is not something you can actually see/ leaves no physical markings, and is difficult to measure quantitatively. This has contributed to its ability to outpace the usage of physical aggression as a conflict tactic among college women 
(Bjorkqvist, 1994). Further, it adds to the normalization of these behaviors within college women's intimate relationships (Katz, Moore, \& Tkachuk, 2007).

Parental Influence. These unique engendered factors reinforce the importance of examining those factors influencing perceptions and experiences with IPV specifically among college women. Prior research in this area has largely focused on the influence of parental socialization and modeling processes on victimization and perpetration. This is because as the most proximal influence on their children, parents' behaviors serve as guidelines and examples that prepare them for intimate relationships (O'Sullivan, MeyerBahlburg, \& Watkins, 2001; Raffaelli, \& Ontai, 2001; Stephens, Fernandez, \& Richman, 2012). Specifically, the Social Learning Theory-based IPV research suggests that children learn appropriate relationship behaviors directly by observing the ways their parents interact (Bandura, 1973; Halford, Sanders, \& Behrens, 2000; Hines \& Saudino, 2002; Kalmuss, 1984; Palazzolo, Roberto, \& Babin, 2010; Skuja \& Halford, 2004). Understanding parental modeling of psychologically aggressive behaviors may provide insight into children's subsequent use and acceptance of these behaviors in their own intimate relationships in adulthood.

When considering Hispanic women of college age, prior research supports the assertion that parental values and behaviors have a significant influence on their daughters' intimate relationship conflict tactics (Brownridge, 2002; Eaton \& Matamala, 2014; Fitzpatrick, et al., 2004). This is in part due to the importance given to familismo, a cultural framework of family importance and "connectiveness," that has been identified as a core value in Hispanic families. The influence of familial, and particularly parental, values has been widely studied in the literature examining Hispanic daughters' intimate 
relationship experiences. For example, prior research has shown that Hispanic parents communicate beliefs about love, acceptance, trust, and intimacy via indirect and direct messaging (Hovell et al., 1994; Raffaelli \& Ontai, 2001; Raffaelli \& Suárez-al-Adam, 1998; Villaruel, 1998). Parental beliefs about these intimacy expectations have implications for understanding Hispanic college women's conflict negotiation tactics with their intimate partners.

Many of these intimate relationship messages from parents to daughters are engendered, and provide insights into culturally specific beliefs about male and female appropriate behaviors. These gender role specific values are important to examine as researchers have found that they can function as a risk factor for aggression in intimate relationships and may lead males to perpetrate both physical and psychological aggression in their intimate relationships, and may lead females to report higher levels of victimization (Brownridge, 2002; Eaton \& Matamala, 2014; Fitzpatrick et al., 2004; Stith \& Farley, 1993). These findings are particularly relevant when considering Hispanic populations as gender frameworks in this culture have traditionally been characterized via concepts of machismo and marianisimo. Machismo is characterized by males' assertion of their dominance, superiority, and strength in relationships (Marrs Fuchsel, Murphy, \& Dufresne, 2012). In contrast, marianismo dictates that women are to be submissive to men in their relationships (Brabeck \& Guzman, 2009; Marrs Fuchsel et al., 2012). By definition, these gender role beliefs allow men to behave in aggressive ways toward their female partners in order to assert and maintain their elevated status (Marrs Fuchsel et al., 2012; Wessel \& Campbell, 1997). 
Building upon prior research which suggests that parental and gender role influences may play key roles in the development of relationship aggression, this dissertation identified the ways in which culturally specific gender identity development variables influence Hispanic college women's experiences with psychological aggression in intimate relationships. Specifically, this dissertation first investigated parents' use of psychological aggression toward their daughter, and participants' beliefs about Hispanic cultural gendered role beliefs. How these are associated with Hispanic college women's psychological aggression victimization within their own intimate relationships was identified. This dissertation also examined these relationships and their association to Hispanic college women's perpetration of psychological aggression within their own intimate relationships. 


\section{LITERATURE REVIEW}

Studies examining college-aged Hispanic women have noted that the rates of IPV victimization are high (Edelson, Hokoda \& Ramos-Lira, 2007; Muñoz-Rivas et al., 2009; Nabors \& Jasinski, 2009; Schnurr et al., 2013). However, few studies have exclusively focused on Hispanic women in college settings. And those studies that focus on college women rarely have large numbers of Hispanic participants (Black et al., 2010; Coker et al., 2002). Further, much of the literature to date examining aggression in intimate relationships within the college student population focuses on physical forms of violence. Moreover, little research has examined the influence of parenting on Hispanic college students' use of aggression in intimate relationships. To address this void, the present review of the literature will bring together the current research identifying potential precursors and correlates of IPV unique to Hispanic college women. This includes aggression in the family of origin, attitudes supporting the use of aggressive tactics during conflict, and traditional gender role beliefs.

\section{Psychological Aggression}

As many as $82 \%$ of college women have reported experiencing victimization of psychological aggression in their intimate relationships (Alleyne-Green et al., 2012; Prospero \& Vohra-Gupta, 2007), and as many as 50\% of racial/ethnic minority women have reportedly perpetrated psychological aggression toward their significant others (Alleyne-Green et al., 2012). Defined as any behavior, threat, or coercive tactic intended to cause psychological/emotional trauma to the victim (CDC, 2014), rates of usage tend to peak in late adolescence and early adulthood, making IPV during this life stage particularly important to investigate further (Capaldi, Knoble, Shortt, \& Kim, 2012). 
Unfortunately, there are few research studies examining psychological aggression which focus on specific sub groups of racial/ethnic minority women. On reason for this is that research investigating aggression in racial/ethnic minority women's intimate relationships has focused on physical forms of aggression (Lehrer, Lehrer, \& Zhao, 2010). This is problematic as it fails to acknowledge the differing forms of violence that exist, particularly those that have been found to be antecedents to physical violence.

Second, as psychological aggression is less obvious than physical aggression, it is often overlooked and discounted in intimate relationships (Katz et al., 2007; Jezl, Molidor, Wright, 1996; Muñoz-Rivas, Graña Gómez, O’Leary, \& González Lozano, 2007). This is not only true within the field but also within couples themselves, as Caetano, Field, Ramisetty-Mikler, and Lipsky (2009) found that over half of the couples they interviewed disagreed about what constituted psychological aggression. Although psychological aggression is often viewed as a less injurious form of aggression than physical tactics (see Williams, Richardson, Hammock, \& Janit, 2012), victims of psychological aggression have reported that it is actually more harmful than physical aggression, in part because its effects tend to be much longer lasting.

Consequences of psychological aggression. Although psychologically aggressive behaviors may go unnoticed or even be normalized, victims of psychological aggression may develop several physical and psychological symptoms. These may include less severe consequences such as embarrassment, anger, or irritation (Infante, Trebing, Shepherd \& Seeds, 1984). However, victims may suffer from many more detrimental symptoms, such as serious damage to their self concept, irritable bowel syndrome, migraine headaches, and chronic pain, post-traumatic stress disorder, anxiety, 
depression, and suicidal ideation (Coker et al., 2000; Hegarty et al., 2004; Infante, et al., 1984; Pico-Alfonso et al., 2006). Suffering from these harmful consequences may, in turn, increase the likelihood that victims of psychological aggression will participate in heavy drug and alcohol use (Coker et al., 2002) and attempt suicide (Pico-Alfonso et al., 2006). Although no studies specifically consider the implications of psychological aggression among Hispanic populations, research on the consequences of other types of IPV have shown that Hispanic victims had significantly greater trauma-related symptoms, depression, lower social and personal self-esteem, and were less likely to make global attributions of positive events when compared to white women of the same age group (see Edelson et al., 2007).

Also important to consider are the long-term patterns of aggression in intimate relationships as research has found that psychological aggression in the family of origin may be predictive of psychological aggression in intimate relationships in adulthood (Black et al., 2010; Murphy \& Blumenthal, 2000). Other studies have shown that engagement in psychological aggression is also linked to the use of physical abuse in adult intimate relationships, suggesting that psychological aggression may be predictive of concurrent or future physical abuse (Hamby \& Sugarman, 1999; O’Leary, 1999; Salis, Salwen, \& O’Leary, 2014; Schumacher \& Leonard, 2005). This supports researchers' assertions that psychological aggression is the first in a long continuum of aggressive behaviors that continue across the lifespan, which includes physical aggression, severe physical aggression, and possible partner/spousal homicide (Murphy \& Blumenthal, 2000; Schumacher \& Leonard, 2005; Winstok, 2006). 


\section{Theories of Intimate Partner Violence}

Given the lack of research examining processes influencing violence perpetration and victimization in Hispanic college women, this study uses two theoretical paradigms to identify underpinnings of this phenomenon. Violence researchers have primarily utilized Social Learning Theory (SLT; Bandura, 1973) when examining various forms of violence within families and intimate relationships across all stage of the lifespan. Social Learning Theory has been widely used because of its focus on attitude development and learning processes that inform violence outcomes in various dyads (Kalmuss, 1984; Skuja \& Halford, 2004; Snethen \& Van Puymbroeck, 2008). Building upon this foundational theory, Social Constructionism (SC; Blume, 1996; Gergen, 1985) has also been utilized as a framework for the examination of multilevel factors influencing psychological aggression experiences within this unique and understudied population. Together, these paradigms will contribute to our understandings of the unique ethnic and cultural values that shape Hispanic college women's interpretations of violence, gender roles, and family processes.

Social Learning Theory. The majority of studies investigating the intergenerational transmission of aggression have used SLT to investigate this phenomenon. Social Learning Theory provides a broad framework for examining aggression, including its triggers and the methods by which individuals attain and maintain its use (Snethen \& Van Puymbroeck, 2008). Social Learning Theory asserts that all individuals are born with the neurophysiological capacity to behave aggressively, but whether they exercise this ability depends on environmental stimulation and level of cortical control (Bandura, 1973). 
Early research on social learning focused mainly on children's use of physical aggression. This research found that children learned appropriate behavior by observing the behavior of models, particularly their primary caregivers (e.g., parents). When these children witness or experience aggression, they become more likely to replicate these behaviors in the future (Bandura, 1973). Because of the attachment and respect children feel towards their primary caregivers, researchers suggest that they are especially likely to replicate behaviors modeled by these individuals (Bandura, 1973; Hines \& Saudino, 2002; Kalmuss, 1984; Skuja \& Halford, 2004).

Following the theoretical assertion that primary caregivers are especially important in children's learning of appropriate behavior through modeling, researchers have utilized SLT to examine the impact of familial violence and aggression on children's understanding and acceptance of appropriate relationship behaviors (Bandura, 1973; Halford et al., 2000; Hines \& Saudino, 2002; Kalmuss, 1984; Skuja \& Halford, 2004; Wekerle \& Wolfe, 1999). These studies have reported findings consistent with SLT. Namely, when one or both parents behave aggressively, this models for children an appropriate response to conflict, consequently increasing their likelihood of using aggression in the future (Bandura, 1973; Halford et al., 2000; Hines \& Saudino, 2002; Kalmuss, 1984; Skuja \& Halford, 2004).

Parent gender appears to be important to whether the modeling of aggressive behavior will result in children's use of subsequent aggressive behavior. Specifically, SLT research suggests that the relationship between parental use of aggression and children's use of aggression in their intimate relationships may be stronger when aggressive behavior is modeled by a same-sex parent (Palazzolo et al., 2010). By 
observing the behavior of their same-sex parent, children learn what constitutes appropriate behaviors for members of their gender, thus constructing gender schemas. Upon observing their same-sex parent's behavior over time, they mentally organize this information in terms of their current gender schemas and/or adapt these schemas as necessary. For instance, Palazzo et al. (2010) found that the modeling of various forms of aggression by fathers had a significantly stronger impact on sons than it did on daughters' subsequent behavior. Likewise, when mothers modeled these same forms of aggression, results showed a significantly stronger impact on daughters' subsequent use of these same aggressive tactics than on sons' use of these tactics.

Social Learning Theory research shows that parental modeling of appropriate behaviors for their children in two distinct ways (Kalmuss, 1984). When parents communicate to children, whether verbally or behaviorally, that aggression is an acceptable way to resolve conflict in the family of origin, they are using what Kalmuss (1984) called generalized modeling. Children then are likely to begin to replicate the specific types of aggressive behaviors that have been modeled in their families, a process which Kalmuss (1984) refers to as specific modeling. While these findings help us to understand the way that children comprehend and are influenced by interparental conflict, there are few studies examining this phenomenon in the normative adult populations broadly, and college populations specifically. Further, this paradigm fails to acknowledge the role of culture in the shaping of understandings of violence and the contexts in which they occur or operate.

Social Constructionism. To understand the ways in which the process of labeling and giving values to IPV within families occurs, it is useful to examine Social 
Constructionism (SC). This paradigm requires that researchers interpret "the process by which people come to describe, explain, or otherwise account for the world in which they live" (Gergen, 1985, p. 3-4). Definitions of behavior are dependent upon who gets to define them, and for what reasons they define it in a particular way. Feminist researchers assert that central to this understanding are the power dynamics surrounding the individuals involved (Blume, 1996; Richardson \& May, 1999). Constructionist theories of violence focus on shared meanings that either justify violent acts or redefine these behaviors so they are acceptable (Blume, 1996). The discourse around violence is formed within a specific context (e.g., the family, society, or culture), thus meanings about violence are defined and redefined by the contexts in which they occur (Blume, 1996). For example, some research has shown that Hispanic women who utilize religious support systems, are not American citizens, or have greater social isolation due to lack of English speaking skills are more likely to accept some level of blame for their domestic violence victimization (Bloom et al., 2009; Klevens, 2007).

Social Constructionism has been an important tool for feminist researchers studying sexual violence and assault. For example, this approach has been used in research seeking to challenge widely accepted definitions of violence to include events that were previously considered acceptable (Kelly \& Radford, 1998; Muehlenhard \& Kimes, 1999). This is evident by the fact that today we have terms to define violence occurring in relationships (e.g., wife rape, wife beating, dating violence). Prior to the 1970's researchers and broader society conceptualized violence as something that occurred between strangers while familial or intimate conflicts were private matters. English common law defined rape as a property crime against men, with women- be it a 
wife or daughter- being men's property (Brownmiller, 1975). Further, as the socially constructed framework of appropriate femininity was/is to be a sexual gatekeeper, women were required to be responsible for men's moral behaviors and sexual decision making at all times - regardless of whether their actions are consensual or nonconsensual. For example, in a study investigating rapists' motivations, Abrahamsen (1960) interviewed their wives to see how they had contributed to their husbands' decision to rape women. Through the use of SC, the rearticulating of the roles that men and women play in these violence processes has led to a reconceptualization of violence. This has, in turn, contributed to shifts in social attitudes, legal responses, and cultural beliefs associated with these behaviors. Along with this, the social category of violence has been expanded to better include the multiple layers that influence its processes (Blume, 1996).

These examples highlight the relevance of gender roles in the social construction of violence. Typically, gender plays a significant role in terms of expectations of ‘behavioral responsibility’ when examining violence victimization and perpetration (Richardson \& May, 1999). On a broader scale, typically women are seen as victims and men as perpetrators of violence. While we cannot ignore the reality of this phenomenon, research has clearly noted that men are more likely to engage in violent behavior than women. However, those that find themselves in positions that juxtapose traditional beliefs about IPV and gender often face negative social consequences. For example, researchers and support services staff (e.g., police, medical services) traditionally viewed college male IPV victimization as non-existent (Stephens \& Eaton, 2014). Further, males were unwilling to report being victims for fear of negative reactions tied to beliefs about 
appropriate gender responses (e.g., disbelief, or homophobic innuendos; Stephens \& Eaton, 2014; Struckman-Johnson \& Struckman-Johnson, 1994, 1996). This reflects the influence of socially constructed gender beliefs individuals hold, and the ways in which they can affect their experiences with IPV. For example, Moreno (2007) found that HIVpositive Hispanic women reconceptualized their IPV experiences as a form of situational abuse that is exacerbated by their HIV status (e.g., threats of deportation).

Clearly, SC can provide a useful perspective for exploring the relevance of unique culturally specific gender role beliefs to IPV in Hispanic college women. Through this framework, how behavior gets defined as violent, under what circumstances, who decides this, and what are deemed appropriate responses can be approached through an examination of engendered cultural values. For Hispanic college women, the combined influence of parental modeling and unique culturally informed gender expectations are important when considering the constructions of meanings and beliefs about violence in this population. As discussed later in this chapter, this paradigm allows for the inclusion of Hispanic cultural values surrounding male gender roles and female gender roles in the study of psychological aggression, in turn acknowledging the existence of differing constructions of violence that may be occurring through engendered processes.

\section{Parental Influence}

Building upon the integration of SLT and SC paradigms, it is important to examine the ways in which parents are the proximal influence in their children's lives. Parent-child interactions play a vital role in modeling appropriate relationship behaviors and interactions for daughters. Parental interactions influence daughters' ideas about themselves as a member of a relationship dyad (O'Sullivan et al., 2001; Raffaelli, \& 
Ontai, 2001; Stephens et al., 2012). This becomes even more salient when examining populations where parental values are viewed as valuable and central to intimate relationship formation, as noted in Hispanic populations (Alleyne-Green et al., 2012; Castillo, Perez, Castillo, \& Ghosheh, 2010).

The current literature examining parental influence on Hispanic daughters' dating behaviors focuses mainly on partner selection (e.g., Buunk \& Solano, 2010), sexuality expectations (e.g., O’Sullivan et al., 2001; Raffaelli, \& Ontai, 2001), and physical aggression (e.g., Lehrer et al., 2010), ignoring the effects of psychological aggression in the parent-child relationship. This is concerning given prior research has clearly shown that direct and indirect parental communications influence intimate relationship behavioral outcomes in Hispanic adolescent and young adult daughters (Dennis, Basañez, \& Farahmand, 2010; Fuligni, Tseng, \& Lam, 1999; Galanti, 2003; Lorenz-Blanco, Unger, Baezconde-Garbanati, Ritt-Olson, Soto, 2012; Unger, Ritt-Olson, Soto, \& BaezcondeGarbanati, 2009; Stephens et al., 2012; Stephens \& Thomas, 2014). Thus, it is important to investigate parental use of psychological aggression in order to assess the ways that this may inform daughters' use and acceptance of psychological aggression in their own intimate relationships.

When parents both directly and indirectly communicate their acceptance, affection, and positive regard through their interactions with each other as well as their interactions with their children, daughters' tend to be involved in more healthy intimate relationships (Andrews, Foster, Capaldi, \& Hops, 2000; Crockett \& Randall, 2006). This further reinforces parental conflict resolution techniques and their daughters' views of appropriate relationship conflict tactics. For example, aversive communication in the 
interparental and parent-child relationships has been found to predict aversive communication, less overall satisfaction, and more physical aggression in children's subsequent intimate relationships. However, some studies have suggested that gender may play a moderating role in this relationship. Specifically, Palazzolo et al. (2010) found that mothers' use of psychological aggression is predictive of daughters' use of psychological aggression in intimate relationships, while fathers' use of psychological aggression is predictive of sons' use of psychological aggression in intimate relationships. Alternatively, other studies have suggested that parental use of aggression in the family of origin may only predict daughters' use of dating violence tactics (Luthra \& Gidycz, 2006).

Hispanic-American parents may be especially at risk for experiencing conflict with their young adult children because of the unique issues they face, such as differences in expectations related to intimate relationship values and behaviors (Dennis et al., 2010; Stephens et al., 2012). Thus it is important to note that expectations regarding abusive behavior or behaviors that deviate from "norms" can vary drastically in form and rate depending on the cultural lenses they are being viewed through (Korbin, 1991). Thus, some researchers point to the importance of acknowledging across and within group differences in beliefs about IPV for men and women. In the Hispanic communities, for example, intimate relationship gender role expectations can differ between men and women depending on various cultural factors such as nationality, acculturation, and geographic region (see Castillo et al., 2010). For example, Stephens and Eaton (2014) found that while Hispanic college men viewed IPV as unacceptable, they perceived female initiated IPV as less harmful when compared to male initiated IPV. Further, less 
acculturated Hispanic males were more likely to hold more traditional views about male IPV perpetration as compared to those who were more acculturated and had attained higher levels of education (Stephens \& Eaton, 2014).

\section{Cultural Influences}

Examining the ways that parental use of aggression may influence young adult children is particularly important in the Hispanic population, as the family, or familismo, is an important socialization institution among this population (Sabogal et al., 1987). Familismo refers to the importance of "connectiveness" in the family and views every individual within the unit as having attachments, reciprocity, and loyalty to family members beyond the boundaries of the nuclear family (Andres-Hyman, Ortiz, Anez, Paris, \& Davidson, 2006).

Familismo has been found to help protect women from IPV victimization since family members- particularly parents- are given privilege and access to intimate relationships and are heavily involved in most social relationships of all family members (see Gonzalez-Guarda, Cummings, Bacerra, Fernandez, \& Mesa, 2013; Howard, Beck, Kerr, \& Shattuck, 2005). However, familismo frameworks also may make it more difficult for victims to leave abusive partners since many family members have a vested interest in the continuation of the nuclear family (Edelson et al., 2007). The messages that Hispanic parents model for their daughters about appropriate behavior in intimate relationships are especially likely to shape their beliefs about IPV (Hovell et al., 1994; Raffaelli \& Ontai, 2001; Raffaelli \& Suárez-al-Adam, 1998; Villaruel, 1998). Thus, it is important to investigate the cultural messaging processes about gender roles and IPV being transmitted within Hispanic familial units. 


\section{Gender Role Beliefs}

Much of the research linking gender role beliefs to relationship aggression has focused on physical abuse (Firestone, Harris, \& Vega, 2003; Harris, Firestone, \& Vega, 2005; Nabors \& Jasinski, 2009), with most research findings indicating that gender roles play an important role in the development of IPV. Harris et al. (2005), for example found that traditional gender role beliefs were related to higher levels of abuse in intimate relationships as well as an increased likelihood that this abuse would go unreported.

Traditional Hispanic Women’s Gender Roles. Gender roles are important to consider in the context of IPV as they are often linked to attitudes and beliefs about the acceptability of violence and aggression. When specifically looking at culturally informed gender roles within Hispanic communities, women are often expected to behave in ways consistent with the femininity framework of marianismo (Castillo et al., 2010; Galanti, 2003). Marianismo is a socially constructed traditional gender role that outlines

the behavioral expectations for Hispanic women. Structured around a patriarchal framework, it encourages women to be passive, submissive, humble, non-sexual, and sacrifice for the good of her family (Castillo et al., 2010). The term itself comes from Catholicism's Virgin Mary, an iconic figure that represents moral integrity, spiritual strength, and self-sacrifice for the benefit of her family (Comas- Diaz, 1995; Galanti, 2003). Tied to this spiritual superiority over men is the belief of her capability to endure suffering and conflict, particularly when inflicted by men (Comas- Diaz, 1995).

These traits inform marianismo beliefs about appropriate familial roles for women; being the perfect wife, mother, and daughter centers on the subordination of 
women in the presence of a heterosexual male authority. The importance of marianismo beliefs can be transmitted to daughters at an early age through direct and indirect modeling. For example, studies on parental socialization processes in traditional Hispanic families have shown young girls are taught to make homemaking and childbearing their key priorities in life (Galanti, 2003). As women age, the importance and roles associated with marianismo also change. While women are thought of as being strong and capable, they are expected not to exert their power outside of the family. More specifically, their limited power should only be exerted within the home for the purpose of caring for the family (Galanti, 2003). This socially constructed concept guides women to be fully dependent on their husbands and as well fulfilling their maternal family responsibilities, making them more vulnerable to patriarchal values and therefore more likely to become oppressed. Denham et al. (2007) found that Hispanic women who experienced IPV were more likely to lack social support and to have children in the home when compared to White populations.

When specifically considering intimate partnerships and IPV, marianismo encourages women to be sexually passive and submissive, accepting male partners' decisions on all sexual matters (Cianelli et al., 2008). These marianismo beliefs directly affect women's ability to negotiate and make decisions during sexual encounters (Davila, Bonilla, Gonzalez-Ramirez, \& Villarruel, 2007; Moreno, 2007). Clearly, this places women in vulnerable positions not only for IPV, but also other negative sexual health outcomes. The influence of marianismo can be so important that it overrides educational and prevention efforts. Villegas et al.'s (2014) study with Chilean women found that traditional marianismo gender role beliefs influenced women's acceptance of 
violence in relationships as a social norm, despite improvements in their IPV prevention education and sense of empowerment. Further, research has shown that even when women in very traditional contexts challenge marianismo beliefs, they can face physical and verbal abuse (Galanti, 2003).

Traditional Hispanic Male Gender Roles. Research on masculinity in Hispanic cultures has traditionally focused on the concept of machismo. This socially constructed framework of masculine gender roles is characterized by authoritarian behavior in the family, including aggressiveness, promiscuity, and virility (Arciniega, Anderson, TovarBlank, \& Tracey, 2008; Salyers Bull, 1998). Although the term is widely used to describe hypermasculinity among other racial/ethnic men of color, machismo as a Hispanic cultural concept is grounded within Christianity-oriented beliefs about patriarchy and appropriate male rights and roles (Brusco, 1995).

The concept of machismo is particularly powerful in sexual contexts, as it has the added expectation that Hispanic men will "prove" their masculinity through their sexuality and sexual performance in various contexts (Ford, Vieira \& Villela, 2003; Galanti, 2003; Glass \& Owen, 2010; Sobralske, 2006b; Torres, Solberg, \& Carlstrom, 2002). Characterized by physical prowess, aggression, toughness, being in charge, and risk taking (Abreau, Goodyear, Campos, \& Newcomb, 2000; Falicov, 2010; Ford et al., 2003; Glass \& Owen, 2010; Sobralske, 2006a), intimate relationship behaviors associated with machismo include having multiple partners, infidelity, controlling one's partners by any means necessary, and sexual risk taking (see Stephens \& Eaton, 2014). Thus, it is important to recognize the implications for placing a high value on machismo as it can foster situations where men utilize hostility and aggression, and place an emphasis on 
obedience, dominance and control with their partners (National Hispanic Healthy Marriage Initiative, 2011).

When specifically looking at IPV, there is a growing body of research specifically examining the intersection between machismo and IPV in North American contexts (e.g., Gonzalez-Guarda, Vasquez, Urrutia, Villarruel, \& Peragallo, 2011; Moreno, 2007; Torres, 1998). Much of this work has focused on the disparity between traditional Hispanic and supposedly “more egalitarian” American gender roles (e.g., Brabeck, \& Guzman, 2009; Coleman- Mason, 2010; Fragoso \& Kashubeck, 2000). This dynamic has been identified as a contributing factor for IPV, as Dutton, Orloff and Aguilar Hass, (2000) found that nearly half of the Hispanics in their study reported an increase in partner violence since their immigration to the United States. It has been suggested that IPV occurs at a much higher rate among Hispanic men oriented toward machismo because they may use violence as a means of establishing power and authority when dealing with a partner holding less traditional gender role views (Davila et al., 2007).

Recently scholars have been moving from just a one dimensional framework of masculinity within Hispanic cultures to examine the influence of both machismo and caballerismo gender role expectations (Arciniega et al., 2008). Behaviors consistent with caballerismo include being chivalrous, proper, and respectful (Arciniega et al., 2008). It also encompasses traits traditionally associated with marianismo, including nurturance, family centeredness, social responsibility, and emotional connectedness. This positive framework of Hispanic masculinity is important as it has been found to serve as a protective factor against the role of machismo on men's self-esteem, coping strategies, 
and positive reframing of negative life incidents (Ojeda \& Liang, 2014; Ojeda \& PiñaWatson, 2014)

Unfortunately, caballerismo is a concept largely ignored in research studies examining health and behavioral outcomes among Hispanic men in the United States. Instead research tends to focus on the more negative aspects of machismo for defining gender role expectations within this population. It has been suggested that this reflects the limited frameworks through which racial/ethnic minority men are viewed, such that dominance, control, and inequality are central characteristics in traditional research examining their sexuality and intimate relationships (Galanti, 2003; Liang, Salcedo, \& Miller, 2011; Stephens \& Eaton, 2014). However, Arciniega and colleagues (2008) assert that both constructs are independent from each other and that it is possible for a man to support caballerismo yet still manifest machismo traits, and vice versa.

Intimate Partner Violence research that has included these two engendered cultural frameworks has found a direct link between caballerismo and the use of adaptive styles of conflict resolution in intimate relationships, while machismo has been found to predict the use of aggression as a conflict resolution tactic in men's intimate relationships (Arciniega et al., 2008; Pardo, Weisfeld, Hill, \& Slatcher, 2012). Research suggests that men who display behaviors consistent with machismo are likely to perpetrate violence toward their intimate partners. For example, Straus (2008) found a positive association between male domination in intimate relationships and male-perpetrated violence toward their significant others. Given the assumption of machismo beliefs possibly being normalized and informing behaviors in Hispanic families, there is a need to identify the 
degree to which psychological aggression is occurring and utilized within Hispanic college students' dating relationships.

\section{Attitudes Toward and Support of IPV}

Taken together, cultural influences and familial processes have been found to shape individuals' attitudes toward and support of IPV. This is important to consider as current research asserts that holding attitudes and beliefs which support the use of intimate partner violence may have both direct and indirect influences on experiences of violence in romantic relationships. This link has been reported for both perpetration (Simmons, Lehmann, \& Cobb, 2008; Stith, Smith, Penn, Ward, \& Tritt, 2004; Tontodonato \& Crew, 1992) and victimization (Machado, Caridade, \& Martins, 2010; Stith et al., 2004). More specifically, research has found that attitudes supporting relationship aggression predicted perpetration of intimate partner aggression by both males (Dardis, Edwards, Kelley, \& Gidycz, 2013; Woodin, Caldeira, \& O’Leary, 2013) and females (Dardis et al., 2013; Edwards, Desai, Gidycz, \& VanWynsberghe, 2009).

There is also a gender component that must be considered as this relationship is further strengthened in males endorsing both traditional gender-roles and attitudes in support of IPV. Specifically, males who were approving of both traditional gender roles and attitudes supporting IPV were more likely to physically assault partners than were those endorsing either traditional gender-role ideology or attitudes supporting relationship violence alone (Reitzel-Jaffe \& Wolfe, 2001). The relationship between attitudes supporting IPV and the perpetration of IPV may be explained by the subconscious operation of these beliefs in the context of intimate partner conflict. More

specifically, Reese-Weber (2008) found males to be more accepting of the perpetration of 
IPV by both males and females. Further, female initiated violence was considered to be more acceptable than male perpetrated violence by both males and females (ReeseWeber, 2008). This means that attitudes that favor the use of IPV may determine individuals' perceptions and acceptance of relationship conflict according to gender perpetration and victimization (Eckhardt, Samper, Suhr, \& Holtzworth-Munroe, 2012; Jouriles, Grych, Rosenfield, McDonald, \& Dodson, 2011).

The acquisition of attitudes favoring the use of aggression in intimate relationships appears to be an important mediator in the intergenerational transmission of intimate partner violence. Several studies have found a link between parental use of aggression in the family of origin, beliefs endorsing the acceptability of aggression in relationships, and involvement in dating violence (O’Keefe, 1998; Temple, Shorey, Tortolero, Wolfe, \& Stuart, 2013). More specifically, aggression in the family of origin appears to be predictive of the acceptance of aggression, which in turn predicts the use of aggression in intimate relationships (O’Keefe, 1998; Temple et al., 2013). The relationship between attitudes endorsing IPV and experiencing IPV in intimate relationships may be particularly strong when aggression is viewed as instrumental (Archer \& Graham-Kevan, 2003), suggesting that these individuals give meaning to violent tactics as being successful methods of achieving their goals.

\section{Current Study}

Clearly, attitudes endorsing the acceptability of IPV may vary by gender and cultural beliefs. Unfortunately, no studies have examined this within Hispanic college populations. To address this void in the literature, this two-part study seeks to identify the ways in which Hispanic college women perpetrate and are victimized by psychological 
aggression in their intimate relationships. Specifically, the role of interparental psychologically aggressive tactics, and culturally specific gender role beliefs will be explored.

Study 1 of the current research explored the relationship between parental use of psychologically aggressive tactics in families of origin, beliefs consistent with machismo and caballerismo, attitudes endorsing boyfriends' use of psychological aggression, and Hispanic college women's psychological aggression victimization in their intimate relationships. It was expected that higher rates of psychological aggression in families of origin, higher levels of machismo beliefs, and higher levels of endorsement of boyfriends' perpetration of psychological aggression will predict higher rates of psychological aggression victimization in Hispanic college women's intimate relationships. It was further expected that holding beliefs consistent with caballerismo will be associated with less psychological aggression victimization in intimate relationships.

Study 2 investigated the relationship between parental use of psychologically aggressive tactics in families of origin, beliefs consistent with marianismo, attitudes endorsing participants' own use of psychological aggression, and Hispanic college women's perpetration of psychological aggression in their intimate relationships. It is expected that higher rates of psychological aggression in families of origin and higher levels of endorsement of participants own perpetration of psychological aggression will predict higher rates of Hispanic college women's perpetration of psychological aggression in their intimate relationships. It is further expected that Hispanic college 
women who hold beliefs consistent with marianismo will report less perpetration of psychological aggression in their intimate relationships.

\section{Hypotheses}

H1: Higher rates of psychological aggression in the family of origin, beliefs consistent with traditional Hispanic male gender roles (i.e., machismo and caballerismo), and attitudes endorsing boyfriends' use of psychological aggression will predict higher rates of victimization of psychological aggression in Hispanic college women's intimate relationships.

H2: Higher rates of psychological aggression in the family of origin, beliefs consistent with traditional Hispanic female gender roles (i.e., marianismo), and attitudes endorsing the acceptability of participants' own use of psychological aggression toward boyfriends will predict higher rates of perpetration of psychological aggression in Hispanic college women's intimate relationships. 


\section{METHODOLOGY}

\section{Participants}

A convenience sample of 687 female Hispanic college students participated in this study. Students between the ages of 18 and 24 were recruited through the Department of Psychology Research pool known as Sona Systems. Participants earned Sona Systems credit for their participation in this study which could be exchanged for course credit. Participants' mean age was 20.87 years $(S D=1.79)$. All participants reported having been in a committed heterosexual relationship in the year prior to their participation and were of Hispanic origin. Familial nations of origin varied widely with $314(45.7 \%)$ self-identifying as Cuban, 75 (10.9\%) self-identifying as Colombian, 50 (7.3\%) self-identifying as Puerto Rican, 43 (6.3\%) self-identifying as Dominican, 42 (6.1\%) self-identifying as Venezuelan, 40 (5.8\%) self-identifying as Nicaraguan, and the remaining $123(17.5 \%)$ self-identifying as being from various South American and Caribbean countries (see Table 1). Nearly half of participants were first generation American (45.4\%), followed by those who were not born in the United States $(32.5 \%)$, those who were second generation American (16.2\%) and those who were third or more generation American (6\%; see Table 2). When responding to questions about their parents' use of psychological aggression, the majority of participants were referring to their biological mothers (99\%; see Table 3) and biological fathers (89.8\%; see Table 4). When considering living situation, the majority of participants were living at home with both parents (55.6\%) or with just their mother (20.4\%; see Table 5). Participants most often reported their mothers' highest level of education to be some college $(24.5 \%)$, followed by a high school diploma/GED (22.6\%), Bachelor's Degree (22\%), Associate's 
Degree (14\%), Master's Degree (8.6\%), and less than high school (4.9\%; see Table 6). When considering fathers' highest level of education, participants most often reported their fathers' highest level of education to be a high school diploma/GED (23.6\%), followed by some college (21.8\%), Bachelor's Degree (20.4\%), Associate's Degree (10.5\%), Master's Degree (9.5\%), and less than high school (8.4\%; see Table 7).

The majority of participants were juniors $(37.3 \%)$, followed by seniors $(29.7 \%)$, sophomores (14.3\%), freshmen (14.1\%), and "senior plus" (4.7\%; see Table 8$)$. When considering their dating status and experience, the majority of participants reported they were in a committed relationship with one person at the time of data collection $(46.7 \%$; see Table 9), and a greater percentage reported having been in one committed relationship in the previous year $(93.4 \%$; see Table 10$)$.

\section{Measures}

Demographic questionnaire. Participants were asked to report demographic information regarding age, nationality, their intimate relationship status, number of committed relationships they have been involved in during the previous 12 months, relationship to the mother and father they referred to in the survey, highest level of education completed by mother and father figures, living situation at the time of survey completion, and year in school.

Age. Participants were asked to report the month and year of their birth in order to calculate their age.

Nationality. Participants were asked to select their nationality from a list of 19 options, including "Cuban," "Colombian," "Puerto Rican," "Venezuelan," "Nicaraguan," "Peruvian," "Mexican," "Dominican," "Honduran," "Argentinean," "Ecuadorian," 
"Chilean," "Panamanian," "Brazilian," "Costa Rican," "Paraguayan," "Uruguayan," "Portuguese," and "Guatemalan." If their nationality was not listed, they also had the option to select "Other" and report their nationality in an open-ended format so as not to limit participants' answers.

Participants' relationship status. Participants were asked to report their relationship status at the time of survey completion in terms of whether they are "Not dating anyone," "Dating one person," "Dating two people," "Dating several people," "I am in a committed relationship with one person," "In a committed relationship with two people," or "Married."

Number of committed relationships involved in. Participants were asked to report the number of self- defined committed relationships they have been involved in over the previous 12 months. They were asked to choose from the following options: "1", "2", "3", or "4 or more."

Year in school. Participants were presented with a drop-down menu and asked to report their year in school based on the number of credits they have obtained. Options presented were "Freshman (0-29)", "Sophomore (30-59)", "Junior (60-89)", and "Senior (90-120)," "Senior Plus (120+).”

Current living situation. Participants' current living situation was assessed by asking whether they presently reside with: "Two parents," "Just my mother," "Just my father," "foster parent(s)," "Aunt or Uncle," "Grandparents," "Significant Other," "Roommate(s)," or "Other."

Relationship to mother figure. Participants were asked whether the mother figure they are referring to in this study is their" biological mother," "adoptive mother," 
"stepmother," "father's girlfriend," "grandmother," "aunt," "godmother," "other," or "not applicable."

Relationship to father figure. Participants were asked whether the father figure they are referring to in this study is their "biological father," "adoptive father," "stepfather," "mother's boyfriend," "grandfather," "uncle," "godfather," "other," or "not applicable."

Highest level of education completed by mother and father figures. Participants were asked to report the highest level of education completed by their mother and father figures. They were presented with the following options: "Less than high school," "High school/GED," "Some college," "2-year college degree (Associate degree)," "4year college degree (BA,BS)," "Master's Degree," "Doctoral Degree," or "Professional Degree (MD, JD).”

Conflict Tactics Scale (CTS2). The Conflict Tactics Scale (CTS2; Straus, Hamby, Bone-McCoy, \& Sugarman, 1996) measures styles of conflict resolution between family members as well as between intimate partners. As we were only interested in parent-participant and participant-boyfriend psychological aggression responses, the current study utilized the psychological aggression items from the Conflict with Parents and Conflict With Intimate Partner forms. The psychological aggression portion of the CTS2 asks respondents questions such as how many times each person involved in the conflict "Shouted or yelled at (the other person)," "Insulted or swore (at the other person)," and "Threatened to hit or throw something (at the other person)." The CTS2 has been shown to have good validity in the factor structure of all aggression subscales (Straus et al., 1996). Straus et al. (1996) reported good internal consistency of 
the psychological aggression subscale, with an alpha of .79. Furthermore, evidence exists to support the construct validity of the CTS2, as the physical and psychological aggression subscales have been shown to be highly correlated, as theoretically expected. Individual forms have not been evaluated for reliability or validity.

The Conflict with Parents form assesses how adolescents/young adults and parents handle conflict with each other. Participants were asked to report the number of times they and their parents had participated in certain actions in response to conflict with each other over the previous year on a scale of 0 (This did not happen during the past year) to 6 (More than 20 times in the past year).

The Conflict with Intimate Partner form includes questions about how participants and their significant others handle conflict with each other. Participants were asked to report the number of times they or their significant others have used certain actions in response to conflict with each other over the previous year on a scale of 0 (This did not happen during the past year) to 6 (More than 20 times in the past year).

Machismo Scale. The Machismo Scale (Arciniega et al., 2008) is composed of two subscales, which include a total of 20 items. The Traditional Machismo subscale asks participants how much they agree with statements such as "Men are superior to women" and "A man should be in control of his wife" on a scale of 1(very strongly disagree) to 7 (very strongly agree). The Caballerismo subscale asked participants to rate how much they agreed with statements such as "Men should be affectionate with their children" and "The family is more important than the individual" using this same Likert scale. Both subscales were found to have good internal consistency. The Traditional Machismo subscale has an $\alpha$ of .85 , and the Caballerismo scale has an $\alpha$ of .80 . The Traditional 
Machismo $(r=.83)$ and Caballerismo $(r=.79)$ subscales also correlated highly with expert ratings.

Marianismo Beliefs Scale. The Marianismo Beliefs Scale (Castillo et al., 2010) is a 24-item measure which was used to assess the extent to which participants agreed with the traditional ideals of marianismo. This scale is comprised of five subscales, including Family Pillar, Virtuous and Chaste, Subordinate to Others, Silencing Self to Maintain Harmony, and Spiritual Pillar. Alpha coefficients of .77, .79, .76, .78, and .85 were found for each of these subscales, respectively.

Intimate Partner Violence Attitudes Scale (IPVAS). The IPVAS (Smith, Thompson, Tomaka, \& Buchanan, 2005) is a 23-item measure used to assess attitudes toward various forms of intimate partner violence. This scale is comprised of three subscales: Abuse, Control, and Physical Violence. Only the Abuse subscale was used in these studies. This subscale was used to assess the extent to which participants agreed with statements such as “Threatening a partner is okay as long as I don’t hurt him”, “I don't mind my partner doing something just to make me jealous", and "It is okay for me to blame my partner when I do bad things" on a scale of 1 (strongly disagree) to 4 (strongly agree). The internal consistency coefficient for this subscale was found to be .81 , and test-retest reliability coefficient (over 14 weeks) was .53 (Fincham, Cui, Braithwaite, \& Pasley, 2008). This subscale was further divided into two subscales. The first assessed participants' endorsement of their own perpetration of psychological forms of violence toward their boyfriends, and the second assessed participants' endorsement of boyfriends' perpetration of this same form of violence toward them. 


\section{Procedure}

Prior to beginning the survey, students were directed to a Qualtrics survey where they were shown a screen containing a Consent Form and asked to click a link acknowledging their consent to participate in the study. Once consent was obtained, students were allowed to complete the online survey anonymously. Upon completing the survey, students were directed back to the Sona Systems website where they were shown a screen containing a confirmation that they had received credit for their participation in the study.

The completed demographic survey and conflict questionnaire data were downloaded from a locked research lab computer in the Principal Investigators' office at Florida International University. All data were entered into an SPSS data file on a computer with a login and access code known only to the Principal Investigators and research assistants.

\section{Primary Analyses}

Simultaneous regressions were used to assess whether parental use of psychological aggression, beliefs endorsing the use of psychological aggression by both participants and their boyfriends in their intimate relationships, and traditional Hispanic gender role beliefs were predictive of actual victimization and perpetration in intimate relationships. Multiple regression analyses were selected in order to allow for the simultaneous analyses of multiple independent variables on the dependent variable of interest in each study. This allows for a more complete picture of the various factors that may contribute to Hispanic college women's experiences with psychological aggression in their intimate relationships. Further, it allows for the assessment of the strength of the 
impact of each of the independent variables on the dependent variable, providing further information regarding the extent to which each of the independent variables in a given model influence the dependent variable of interest.

Prior to running multiple regression analyses, the data was assessed to check for multicollinearity. This was done in order to ensure that variables were sufficiently independent of one another. This is vital as it prevents potential distortions in the beta weights provided by the multiple regression analyses, which are likely to occur in the presence of multicollinearity. Multicollinearity was assessed using three methods. First, Pearson correlations were assessed to ensure that all correlation coefficients were smaller than .08 (see Tables 11 and 12). Tolerance levels were then checked to ensure that all tolerance levels were above .20 (see Tables 13 and 14). Finally, the variance inflation factor (VIF) was assessed to ensure that all scores were below 10 (see Tables 13 and 14). These analyses showed that there was no multicollinearity between any of the independent variables in either Study 1 or Study 2. 
IV. STUDY 1 -Women's Psychological Aggression Victimization

\section{Results}

Table 15 presents the means and standard deviations for all of the continuous variables included in study 1 . The median values for each of the variables (not reported) were close to the mean values. The majority of participants reported holding beliefs endorsing their boyfriend's perpetration of psychological aggression toward them (72.9\%; see Table 16). When considering traditional gender role beliefs, participants' mean score on the Machismo Subscale was 20.21 ( $S D=8.16$, range: 8-51; see Table 17), and 25.97 on the Caballerismo Subscale ( $S D=18.32$, range: $0-60$; see Table 18).

A total of $74.1 \%$ and $45.4 \%$ of participants reported experiencing psychological aggression perpetrated by their mothers and fathers, respectively, at least once in the past year (see Tables 19 and 20). The majority (63.2\%) reported that their boyfriends had perpetrated psychological aggression toward them at least once in the past year (see Table 21).

Outliers were evaluated prior to analysis by calculating a mean leverage score for each participant based on their multivariate profile for the six variables included in study 1. The mean leverage score across respondents for study 1 was .007 . An outlier was defined as anyone having a leverage score four times the value of the mean. A small number of outliers were found and discarded $(\mathrm{N}=11)$. The model contained no missing data.

Study 1 used a simultaneous multiple regression analysis to test the hypothesis that mothers' perpetration of psychological aggression toward daughters, fathers' perpetration of psychological aggression toward daughters, daughters' beliefs consistent 
with machismo, daughters' beliefs consistent with caballerismo, and daughters' beliefs endorsing their boyfriends' perpetration of psychological aggression toward them would each predict the actual victimization of psychological aggression that daughters' experienced in their intimate relationships. Figure 1 visually represents the model used for Study 1. The results of the regression indicated that the 5 predictors explained $7.3 \%$ of the variance $\left(\mathrm{R}^{2}=.07, \mathrm{~F}(5,681)=10.78, p<.001\right)$. Analyses were conducted to test the unique contribution of each predictive variable on the dependent variable. When looking specifically at the parental variables, fathers' perpetration of psychological aggression towards daughters significantly predicted daughters' psychological aggression victimization in their intimate relationships $(\beta=.20, p<.05)$, as did mothers' perpetration of psychological aggression toward daughters $(\beta=.08, p<.05)$. When looking specifically at the gender role variables, beliefs consistent with caballerismo was found to negatively predict daughters' psychological aggression victimization in their intimate relationships $(\beta=-.08, p<.05)$, while beliefs consistent with machismo did not significantly predict daughters' psychological aggression victimization in their intimate relationships $(\beta=-.07$, $p=.06$ ). Finally, results showed that beliefs endorsing boyfriends' perpetration of psychological aggression toward participants did not significantly predict participants' psychological aggression victimization $(\beta=.03, p=.38)$.

\section{Discussion}

Study 1 investigated the hypothesis that mothers' and fathers' perpetration of psychological aggression toward daughters, daughters' beliefs consistent with machismo and caballerismo, and daughters' beliefs endorsing their boyfriends' perpetration of psychological aggression toward them would predict the actual victimization of 
psychological aggression that daughters experience in their intimate relationships. The results of this study provided partial support for this hypothesis.

First, parents' use of psychological aggression toward daughters significantly predicted daughters' victimization of psychological aggression by boyfriends. This finding is consistent with past research and SLT frameworks which assert that parents' behavior toward daughters influences their ideas about themselves as members of a relationship dyad (Palazzolo et al., 2010; Stephens et al., 2012). Specifically, SLT research examining IPV has asserted that parents serve to model appropriate behaviors for their sons and daughters, including conflict tactics and appropriate relationship behaviors. Further, because of the value that Hispanic families tend to place on family connectiveness, Hispanic daughters are more likely to repeat and normalize behaviors modeled by their parents.

It is also particularly noteworthy that fathers' perpetration of psychological aggression toward daughters was the strongest predictor of daughters' victimization of psychological aggression in their intimate relationships. This again supports the SLT assertion that women may "learn" appropriate and acceptable male behavior through interactions with their fathers and the modeling of their fathers' behaviors. Although Hispanic fathers exert less control over their children in shared kinship contexts when compared to White fathers, they tend to be more involved in childrearing (Hofferth, 2003). This involvement, particularly for daughters, increases the level of communication, modeling, and influence they have on perceptions of interpersonal relationship development (Hofferth, 2003). Future research should build upon these results to focus specifically on Hispanic father-daughter relationships given the 
importance of familial processes and paternal influence noted in previous research (Hofferth, 2003; Raffaelli \& Ontai, 2001; Raffaelli \& Suárez-al-Adam, 1998; Villaruel, 1998).

Mothers' perpetration of psychological aggression toward daughters was also significantly predictive of women's psychological aggression victimization in their intimate relationships. As noted in the previous discussion about the influence of fathers' psychological aggression, it is clear that SLT can contribute to our understandings of this result. This finding opens the door to future research examining reciprocal relationship aggression. While this study did not specifically assess female perpetration, this result suggests that it is possible that victimization is impacted indirectly via reciprocal relationship aggression. More specifically, mothers' use of psychological aggression toward daughters may predict daughters' perpetration of psychological aggression, thus making it more likely that they will also be victimized by this same type of aggression. This is consistent with prior research, which suggests that relationship aggression tends to be reciprocal in nature (Atkin et al., 2002; Infante et al., 1990; Rancer \& Avtgis, 2006). It appears that when one member of a relationship dyad uses psychological aggression, it may prompt the other member to retaliate using an equally aggressive tactic, creating a potential cycle of psychological aggression within the relationship (Atkin, et al., 2002; Infante, et al., 1990). While this is an important finding, there is still a void in the knowledge about this phenomenon as it specifically relates to Hispanic women's experiences. [This question is addressed in Study 2, which investigates this potential direct relationship between mothers' use of psychological aggression toward daughters' and daughters' perpetration of psychological aggression toward their boyfriends.] 
When considering the role of traditional Hispanic gender role beliefs, results showed that caballerismo significantly predicted less victimization of psychological aggression in participants' intimate relationships. This suggests that holding beliefs consistent with caballerismo, which dictates that men should be chivalrous, proper, and respectful (Arciniega et al., 2008), may serve as a protective factor against women's psychological aggression victimization. This highlights the ways in which SC theory notes the importance of context and culture in shaping understandings of IPV (Blume, 1996). Specifically, SC would assert that Hispanic women would give positive meaning to what feminist researchers traditionally label as benevolent sexism actions. Caballerismo shares many characteristics with benevolent sexism, which asserts that women require the protection of men (Falicov, 2010). Both caballerismo and benevolent sexism perpetuate power inequities between men and women, requiring women to behave submissively.

Interestingly, while caballerismo was significantly related to women's psychological aggression victimization in their intimate relationships, machismo was not. In other words, holding beliefs consistent with machismo did not significantly predict women's psychological aggression victimization in their intimate relationships. It is possible that although they believe that men are expected to behave in ways consistent with machismo, such as displaying dominance, superiority, and strength (Marrs Fuchsel et al., 2012), this may not mean they accept these behaviors in their intimate relationships. Clearly, SC theory's assertions regarding culturally and contextually unique influences on the creations of IPV meanings is important to examine here. Specifically, prior research has noted marianismo, machismo and caballerismo gender 
role frameworks play an important role in Hispanic emerging adults intimate relationship processes (CDC, 2014; Marrs Fuchsel et al., 2012; Wessel \& Campbell, 1997). Through the identification of the meanings and perceptions women hold about machismo and caballerismo research can better address the ways in which these masculinity beliefs impact experiences with psychological aggression, specifically, and IPV, broadly.

Holding beliefs endorsing boyfriends' perpetration of psychological aggression did not significantly predict participants' actual victimization of psychological aggression. This result suggests that women's acceptance of male perpetrated aggression does not put them at risk for victimization in their intimate relationships. This finding may be explained by prior research which shows that psychological aggression often goes unrecognized and may therefore go unreported by victims in intimate relationships. Future research should examine this relationship from the perspective of both partners in an intimate relationship to get a better understanding of the levels and types of psychological aggression that may be occurring in Hispanic college women's intimate relationships.

This finding also reinforces the need for research examining the diverse gender role beliefs within Hispanic communities and their relevance to IPV. Specifically, this study's finding regarding machismo points to the fact that the support of highly traditional masculinity gender roles, including beliefs that endorse male aggression toward women, has little effect on women's victimization of psychological aggression in their intimate relationships. SC theory would be a useful framework for guiding future research examining whether the acceptability of male-perpetrated aggression would increase women's willingness to remain in long-term abusive relationships. Clearly, there 
are unique meanings and understandings about male-female gender roles, particularly as it relates to masculinity expectations; SC theory would be useful for guiding the identification of these subtle, culturally specific gender role nuances. 
V. STUDY 2 - Women's Perpetration of Psychological Aggression

\section{Results}

Table 22 presents the means and standard deviations for all of the continuous variables included in Study 2. The median values for each of the variables (not reported) were close to the mean values. The majority of participants reported holding beliefs endorsing their perpetration of psychological aggression toward their boyfriends $(78.5 \%$; see Table 23). Participants' mean score on the Marianismo Beliefs Scale was 52.40 $(S D=10.01$, range: $24-93$; see Table 24$)$. Further, the majority $(73.7 \%)$ of participants reported having perpetrated psychological aggression toward their boyfriends at least once in the past year (see Table 25).

Outliers were evaluated prior to analysis by calculating a mean leverage score for each participant based on their multivariate profile for the five variables included in study 2. The mean leverage score across respondents was .006 for study 2. An outlier was defined as anyone having a leverage score four times the value of the mean. A small number of outliers were found and discarded $(\mathrm{N}=23)$. The model contained no missing data.

Study 2 used a simultaneous multiple regression analysis to analyze the predictive roles of mothers' perpetration of psychological aggression toward daughters, fathers' perpetration of psychological aggression toward daughters, daughters' beliefs consistent with marianismo, and daughters' beliefs endorsing their own perpetration of psychological aggression toward boyfriends on daughters' actual perpetration of psychological aggression in their intimate relationships. Figure 2 visually represents the model used for Study 2. The results of the regression indicated that the 4 predictors 
explained $10.8 \%$ of the variance $\left(\mathrm{R}^{2}=.10, \mathrm{~F}(4,682)=20.75, p<.001\right)$. Analyses were conducted to test the unique contribution of each predictive variable on the dependent variable. Fathers' perpetration of psychological aggression toward daughters significantly predicted daughters' perpetration of psychological aggression in their intimate relationships $(\beta=.12, p<.05)$, as did mothers' perpetration of psychological aggression toward daughters $(\beta=.19, p<.05)$ and beliefs endorsing their own perpetration of psychological aggression toward their intimate partners $(\beta=.17, p<.05)$. Further, results showed that beliefs consistent with marianismo negatively predicted participants' perpetration of psychological aggression in their intimate relationships $(\beta=-.08, p<.05)$.

\section{Discussion}

Study 2 investigated the hypothesis that mothers' and fathers' perpetration of psychological aggression toward daughters, daughters' beliefs consistent with marianismo, and daughters' beliefs endorsing their perpetration of psychological aggression toward their boyfriends would predict their actual perpetration of psychological aggression in their intimate relationships. The results of this study supported this hypothesis.

Results showed that mothers' and fathers' use of psychological aggression toward daughters significantly predicted daughters' perpetration of psychological aggression toward their boyfriends. Overall, mothers' use of psychological aggression was the strongest predictor of daughters' perpetration of psychological aggression in their intimate relationships. These results are consistent with SLT, which states that individuals learn appropriate behavior from parents, who serve as models (Bandura, 1973; Halford et al., 2000; Hines \& Saudino, 2002; Palazzolo et al., 2010; Skuja \& 
Halford, 2004). This is particularly true when these behaviors are modeled by same-sex parents. It appears that when mothers use psychological aggression, daughters learn to view it as an appropriate response to conflict through the process of specific modeling (Kalmuss, 1984). This is consistent with past research which shows that mothers' use of psychological aggression predicts daughters' use of psychological aggression in their intimate relationships (Palazzolo et al., 2010).

Results further showed that holding beliefs endorsing their perpetration of psychological aggression also significantly predicted women's actual perpetration of psychological aggression toward their boyfriends. More specifically, women who believe it is acceptable for them to perpetrate psychological aggression in their intimate relationships are significantly more likely to behave in ways consistent with this belief. This is consistent with prior research which shows that women who believe aggression is acceptable in intimate relationships are more likely to perpetrate aggression toward their significant others (Singer, 2003; Temple et al., 2013).

This finding contributes to the research on SC and IPV, which has shown that culturally constructed understandings of violence are always changing across groups and over time (Blume, 1996). Traditionally, women were not viewed as perpetrators of aggression; we know that this has significantly changed over time. Some researchers suggest that women use this form of IPV because it does not require significant physical strength and may therefore be a relatively easy, yet effective, conflict tactic for them to carry out (Bjorkqvist, 1994). Others note that society has shifted such that women are increasingly becoming more violent across all forms of aggression (Eaton \& Matamala, 2014; Stephens \& Eaton, 2014). Given the significant increase in women's use of these 
aggressive tactics, there is a need for more research like this to examine what factors are influencing their increased acceptability of the perpetration of psychological aggression.

The finding that holding beliefs consistent with marianismo negatively predicted participants' perpetration of psychological aggression in their intimate relationships contributes to our understandings of the importance of gender role beliefs in IPV. This finding suggests that holding beliefs consistent with marianismo may protect against women's perpetration of psychological aggression in their intimate relationships. This result may be reflective of the marianismo characteristics that expect women to be submissive in their relationships with men (Brabeck \& Guzman, 2009; Marrs Fuchsel et al., 2012). By definition, a woman that is accepting of marianismo would not engage in aggressive tactics as a means of ensuring her partner maintains his reciprocal machismo elevated status (Marrs Fuchsel et al., 2012; Wessel \& Campbell, 1997). Thus, the question arises of whether it is a buffer for engagement in psychological aggression or simply reflects their submissiveness in the face of traditional gender role expectations. Thus future research should investigate the relationship between marianismo and victimization to determine whether women's beliefs that they should be submissive to men put them at risk for the victimization of aggression in intimate relationships. 


\section{GENERAL DISCUSSION}

\section{Summary}

The current dissertation sought to evaluate the influence of parental use of psychological aggression, traditional Hispanic gender role beliefs (i.e., marianismo, machismo, and caballerismo), and attitudes endorsing the use of psychological aggression on Hispanic college women's experiences with psychological aggression in their intimate relationships. No studies to date investigating psychological aggression have focused exclusively on Hispanic women, particularly when considering their victimization and perpetration of this type of aggression in their intimate relationships. In an attempt to fill this void in the literature, the current dissertation investigated several possible contributors to Hispanic college women's experiences with psychological aggression with their boyfriends, including familial, cultural, and attitudinal factors.

Study 1 investigated the roles of parental use of psychological aggression, beliefs consistent with machismo and caballerismo, and attitudes endorsing boyfriends' use of psychological aggression in Hispanic college women's psychological aggression victimization in their intimate relationships. Results of this study show that both mother's and father's use of psychological aggression are predictive of participants' psychological aggression victimization in their intimate relationships. This finding is consistent with SLT's assertion that relationship behaviors are modeled by parents in the family of origin (Cui, Durtschi, Donnellan, Lorenz, \& Conger, 2010; Luthra \& Gidycz, 2006; Palazzolo et al., 2010). Further, the results of this study suggest that holding beliefs consistent with caballerismo appears to serve as a protective factor against psychological aggression victimization in intimate relationships. This finding lends support to $\mathrm{SC}$, which 
acknowledges the key role of gender role beliefs on the social construction of aggression and its appropriateness. However, results also found that machismo beliefs and attitudes endorsing the acceptability of psychological aggression did not significantly predict participants' victimization in their intimate relationships. Further research is needed to investigate the potential long term impacts of these variables longitudinally on Hispanic college women's experiences with psychological aggression.

Study 2 investigated the roles of parental use of psychological aggression, beliefs consistent with marianismo, and attitudes endorsing participants' own use of psychological aggression on their perpetration of psychological aggression in their intimate relationships. The results of this study show that mothers' and fathers' use of psychological aggression and attitudes endorsing participants' use of psychological aggression significantly predicted participants' perpetration of psychological aggression toward their boyfriends. These results lend support to SLT's assertion that parents serve as models for appropriate relationship behaviors. Further, holding beliefs consistent with marianismo appears to serve as a protective factor against the perpetration of psychological aggression in intimate relationships. This is consistent with SC which asserts that gender role beliefs influence the acceptability of violence within relationships. Because marianismo dictates that women should behave submissively toward their male significant others, it stands to reason that they may be less inclined to use aggressive tactics when in conflict with them.

\section{Limitations}

Although this study provides foundational research information about an understudied population and phenomenon, there are limitations that must be considered. 
First, when considering the methodology, the use of online data collection methods limited participants' ability to ask questions that may have arisen while completing the survey, and decreased their ability to provide more meaningful or detailed explanations about their answers. These factors have been found in previous research to affect the accuracy in the data (see Lefever, Dal, \& Matthíasdóttir, 2007). For instance, while participants were asked to report experiences of psychological aggression in their committed relationships, this term was not defined for them and was thus left open to their interpretation. This may consequently lead to inconsistencies in the data, as participants may have differing ideas of what constitutes a committed relationship. Online data collection has many benefits, however, such as access to a large pool of participants and the ability for participants to respond to questionnaires entirely anonymously, which is particularly important when disclosing sensitive information. Future research should replicate these studies using paper surveys in order to assess any differences in findings that may exist.

Another potential methodological limitation is that data about parental and partner aggression was only collected from the perspective of the one participant. As a result, only the participants' recollections of psychological aggression in these relationship dyads are provided. Future research should replicate these studies using data from parents and significant others as well as participants to investigate any differences that may exist between participants' perceptions of aggression and parents' and boyfriends' reports of aggression.

Similarly, there is a need for greater depth in questioning about the quality and quantity of relationship interactions. For example, mothers were found to be a more 
significant influence than fathers on daughters' perpetration of psychological aggression in intimate relationships while fathers were a more significant influence on daughters' victimization than were mothers. While this is an important finding, it does not address the fact that these differences between mother and father were statistically nonsignificant. This is assumed to be primarily due to methodological limitations where the specific living situations (e.g. time spent at home, amount of time spent interacting, influence of other family members in the home, influence of step-parents, etc.) and quality of the mother-daughter and father-daughter relationships were not assessed. Future work should tease out perceptions of these relationships and separately examine the experiences of the $76 \%$ of daughters living with mothers and the $57.6 \%$ living with fathers.

A final methodological consideration would be that these data are not longitudinal. While this makes it difficult to definitively pinpoint the temporal order of variables, the current studies provide preliminary insight into the relationships between the independent and dependent variables. Future studies should assess these relationships using longitudinal data in order to better understand how parental use of psychological aggression, traditional Hispanic gender role beliefs, and attitudes endorsing the use of psychological aggression influence Hispanic college women's experiences with psychological aggression in their intimate relationships long-term.

There are also demographic limitations that must be considered. For example, the majority of participants reported residing with one or both parents, a living situation that is not viewed in the current research as typical of college students (see Bishaw, 2013). This reality may have also influenced their perceptions of psychological aggression as 
they have ongoing and increased exposure to their parental relationships. Students who are not residing at home may have differing recollections and experiences. Further, given that college is a period of transition toward greater independence, there is the possibility of increased or new conflicts about the changing nature of the parent-child roles (Flannagan, Schulenberg, \& Fuligni, 1993).

There is also a need for examination of within-group differences and experiences with psychological aggression. For example, it is plausible that these findings would differ if the sample were larger or more diverse (e.g., Afro-Hispanics, sexual minority Hispanic women). Further, these women attended a HSI in an urban center where over $60 \%$ of the population self-identifies as Hispanic. As such, the findings may not be applicable to those living outside the college context or region where this research took place. Future research must be attuned to these diverse identifications among Hispanic college populations.

\section{Conclusions}

Despite these limitations, this study provides new insights regarding Hispanic college women's experiences with psychological aggression. There was clear support for the notion that parental use of psychological aggression, traditional female gender role beliefs, and attitudes endorsing the use of psychological aggression impacted women's perpetration of psychological aggression in their intimate relationships. Further, parental use of psychological aggression and beliefs consistent with caballerismo impacted women's psychological aggression victimization in their intimate relationships. These findings enhance our knowledge about a significantly understudied population, which constitutes the largest group of ethnic minority women on college campuses across the 
United States (Fry, 2011). This contributes to our ability to understand the process by which Hispanic college women come to experience psychological aggression in their intimate relationships. Specifically, Study 1 contributes to the literature of psychological aggression victimization in Hispanic college women's relationships, while Study 2 contributes to the literature on the perpetration of psychological aggression in this population. The findings of these studies assists in further understanding processes of aggression in Hispanic populations and may contribute to the development of prevention programs aimed at this population, which may be particularly at risk for intimate partner aggression. This also points to the need for future research to specifically assess acculturation and its impact on gender identity and IPV perceptions. 


\section{REFERENCES}

Abrahamsen, D. (1960). The psychology of crime. New York: Columbia University Press.

Abreau, J. M., Goodyear, R. K., Campos, A., \& Newcomb, M. D. (2000). Ethnic belonging and traditional masculinity ideology among African Americans, European Americans, and Latinos. Psychology of Men \& Masculinity, 1, 75-86.

Alleyne-Green, B., Coleman-Cowger, V. H., Henry, D. B. (2012). Dating violence perpetration and/or victimization and associated sexual risk behaviors among a sample of inner-city African American and Hispanic adolescent females. Journal of Interpersonal Violence, 27(8), 1457-1473.

Andres-Hyman, R. C., Ortiz, J., Anez, L.M., Paris, M., \& Davidson, L. (2006). Culture and clinical practice: Recommendations for working with Puerto Ricans and other Latinas(os) in the United States. Professional Psychology: Research and Practice, 37, 694-701.

Andrews, J. A., Foster, S. L., Capaldi, D., \& Hops, H. (2000). Adolescent and family predictors of physical aggression, communication, and satisfaction in young adult couples: A prospective analysis. Journal of Consulting and Clinical Psychology, 68, 195208.

Archer, J. (2000). Sex differences in aggression between heterosexual partners: A metaanalytic review. Psychological Bulletin, 126(5), 651-680.

Arciniega, G. M., Anderson, T. C., Tovar-Blank, Z. G., \& Tracey, J. G. (2008). Toward a fuller conception of machismo: Development of a traditional machismo and Caballerismo scale. Journal of Counseling Psychology, 55(1), 19-33.

Atkin, C., Smith, S., Roberto, A., Fediuk, T., \& Wagner, T. (2002). Correlates of verbally aggressive communication in adolescents. Journal of Applied Communication Research, $30(3), 251-268$

Bandura, A. (1973). Aggression: A social learning analysis. Englewood Cliffs, NJ: Prentice-Hall.

Basow, S. A., Cahill, K. F., Phelan, J. E., Longshore, K., \& McGillicuddy-DeLisi, A. (2007). Perceptions of relational and physical aggression among college students: Effects of gender of perpetrator, target, and perceiver. Psychology of Women Quarterly, 31, 8595.

Basuk, E., Dawson, R., \& Huntington, N. (2006). Intimate partner violence in extremely poor women: Longitudinal patterns and risk markers. Journal of Family Violence, 21(6), 387-399. 
Bishaw, A. Examining the Effect of Off-Campus College Students on Poverty Rates. SEHSD 2013-17. U.S. Census Bureau, Social, Economic \& Housing Statistics Division, Poverty Statistics Branch.

Bjorkqvist, K. (1994). Sex differences in physical, verbal, and indirect aggression: A review of recent research. Sex Roles, 30, 177-188.

Black, D. S., Sussman, S., Unger, J. B. (2010). A further look at the intergenerational transmission of violence: Witnessing interparental violence in emerging adulthood. Journal of Interpersonal Violence, 25, 1022-1042.

Bloom, T., Wagman, J., Hernandez, R., Yragui, N., Hernandez-Valdovinos, N., Dahlstrom, M., \& Glass, N. (2009). Partnering with community-based organizations to reduce intimate partner violence. Hispanic Journal of Behavioral Sciences, 31(2), 244257.

Blume, T. (1996). Social Perspectives on Violence. Michigan Family Review, 2, 9- 23.

Blumenthal, D. R., Neemann, J., \& Murphy, C. M. (1998). Lifetime exposure to interparental physical and verbal aggression in college students. Violence and Victims, 13 (2), 175-195.

Brabeck, K. M. \& Guzman, M. R. (2009). Exploring Mexican-origin intimate partner abuse survivors' help-seeking within their sociocultural contexts. Violence and Victims, 24(6), 817-832.

Brown, A., \& Lopez, M. H. (2013). Mapping the Latino population, by state, county, and city. Washington, DC: Pew Hispanic Center.

Brownmiller, S. (1975). Against our will: Men, women, and rape. New York: Bantam.

Brownridge, D. A. (2002). Cultural variation in male partner violence against women: A comparison of Quebec with the rest of Canada. Violence Against Women, 8, 87-115.

Brusco, E. E. (2010) The reformation of machismo: Evangelical conversion and gender in Colombia. Austin: Univ. of Texas Press.

Buunk, A. P. \& Solano, A. C. (2010). Conflicting preferences of parents and offspring over criteria for a mate: A study in Argentina. Journal of Family Psychology, 24, 391399.

Caetano, R., Field, C., Ramisetty-Mikler, S., \& Lipsky, S. (2009). Agreement on reporting of physical, psychological, and sexual violence among White, Black, and Hispanic couples in the United States. Journal of Interpersonal Violence, 24(8), 13181337. 
Caetano, R., Ramisetty-Mikler, S., Caetano Vaeth, P. A., \& Harris, T. R. (2007).

Acculturation stress, drinking, and intimate partner violence among Hispanic couples in the U.S. Journal of Interpersonal Violence, 22, 1431-1447.

Caetano, R.,Ramisetty-Mikler, S., \& McGrath, C. (2004). Acculturation, drinking, and intimate partner violence among Hispanic couples in the United States: A longitudinal study. Hispanic Journal of Behavioral Sciences, 26(1), 60-78.

Caetano, R., Schafer, J., Clark, C. L., Cunradi, C. B., \& Raspberry, K. (2000). Intimate partner violence, acculturation, and alcohol consumption among Hispanic couples in the United States. Journal of Interpersonal Violence, 15(1), 30-45.

Capaldi, D. M., Kim, H. K., \& Shortt, J. W. (2007). Observed initiation and reciprocity of physical aggression in young, at-risk couples. Journal of Family Violence, 22(2), 101111.

Capaldi, D. M., Knoble, N. B., Shortt, J. W., \& Kim, H. K. (2012). A systematic review of risk factors for intimate partner violence. Available Online: Partner Abuse.

Capezza, N. M. \& Arriaga, X. B. (2008). Factors associated with acceptance of psychological aggression against women. Violence Against Women, 14(6), 612-633.

Castillo, L. G., Perez, F. V., Castillo, R., \& Ghosheh, M. R. (2010). Construction and initial validation of the marianismo beliefs scale. Counseling Psychology Quarterly, 23, $163-175$.

Centers for Disease Control and Prevention. (2014). Intimate Partner Violence in the United States - 2010. Retrieved from http://www.cdc.gov/violenceprevention/pdf/cdc_nisvs_ipv_report_2013_v17_single_a.pd $\mathrm{f}$

Coker, A. L., Sanderson, M., Cantu, E., Huerta, D., \& Fadden, M. (2008). Frequency and types of partner violence among Mexican American college women. Journal of American College Health, 56 (6), 665-674.

Coker, A, L., Smith, P. H., Bethea, L., King, M. R., McKeown, R. E. (2000). Physical health consequences of physical and psychological intimate partner violence. Archives of Family Medicine, 9, 451-457.

Coker, A. L. et al. (2002). Physical and mental health effects of intimate partner violence for men and women. American Journal of Preventative Medicine, 23, 260-268.

Coleman- Mason, A. (2010). Providing human services to Latina immigrants: Victims of IPV. Human Services Today, 6, http://hst.coehs.uwosh.edu 
Comas-Diaz, L. (1995). Puerto Ricans and sexual child abuse. In L.A. Fontes (Ed.), Sexual abuse in nine North American cultures: Treatment and prevention (pp. 31-66). Thousand Oaks, CA: Sage.

Crockett, L. J. \& Randall, B. A. (2006). Linking adolescent family and peer relationships to the quality of young adult romantic relationships: The mediating role of conflict tactics. Journal of Social and Personal Relationships, 23, 761-780.

Cui, M., Durtschi, J. A., Donnellan, M. B., Lorenz, F. O., \& Conger, R. D. (2010). Intergenerational transmission of relationship aggression: A prospective longitudinal study. Journal of Family Psychology, 24, 688-697.

Cummings, E. M., Goeke-Morey, M. C., \& Papp, L. M. (2003). Children's responses to everyday marital conflict tactics in the home. Child Development, 74, 1918-1929.

Cunradi, C. B. (2009). Intimate partner violence among Hispanic men and women: The role of drinking, neighborhood disorder, and acculturation-related factors. Violence and Victims, 24(1), 83-97.

Dardis, C. M., Edwards, K. M., Kelley, E. L., \& Gidycz, C. A. (2013). Dating violence perpetration: The predictive roles of maternally versus paternally perpetrated childhood abuse and subsequent dating violence attitudes and behaviors. Journal of Aggression, Maltreatment \& Trauma, 22, 6-25.

Davila, Y. R., Bonilla, E., Gonzalez-Ramirez, D., Villarruel, A. M. (2007). HIV-IPV prevention: Perceptions of what Latinas want and need. Hispanic Health Care International, 5(3), 101-108.

Denham, A.C., Frasier, E.G., Hooten, E.G., Belton, L., Newton, W., Gonzalez, P., Begum, M., \& Campbell, M. K. (2007). Intimate partner violence among Latinas in eastern North Carolina Violence Against Women, 13, 123-140.

Dennis, J., Basañez, T. \& Farahmand, A. (2010). Intergenerational conflicts among Latinos in early adulthood: Separating values conflicts with parents from acculturation conflicts. Hispanic Journal of Behavioral Sciences, 32, 118-135.

Derrick, J. L., Testa, M., \& Leonard, K. E. (2014). Daily reports of intimate partner verbal aggression by self and partner: Short-term consequences and implications for measurement. Psychology of Violence, 4(4), 416-431.

Dowd, L. S., Leisring, P. A., \& Rosenbaum, A. (2005). Partner aggressive women: Characteristics and treatment attrition. Violence and Victims, 20(2), 219-33. 
Dutton, M., Orloff, L., \& Aguilar Hass, G. (2000). Characteristics of help-seeking behaviors, resources, and services needs of battered immigrant Latinas: Legal and policy implications. Georgetown Journal on Poverty Law and Policy, 7(2), 245-305.

Eaton, A. A., \& Matamala, A. (2014). The relationship between heteronormative beliefs and verbal sexual coercion in college students. Archives of Sexual Behavior, doi:http://dx.doi.org/10.1007/s10508-014-0284-4.

Eckhardt, C. I., Samper, R., Suhr, L., \& Holtzworth-Munroe, A. (2012). Implicit Attitudes Toward Violence Among Male Perpetrators of Intimate Partner Violence A Preliminary Investigation. Journal of interpersonal violence, 27(3), 471-491.

Edelson, M. G., Hokoda, A., \& Ramos- Lira, L. (2007). Differences in effects of domestic violence between Latina and non-Latina women. Journal of Family Violence, 22, 1-10.

Falicov, C. (2010). Changing constructions of machismo for Latino men in therapy: "The devil never sleeps". Family Process, 49, 309-329.

Fincham, F. D. \& Beach, S. R. H. (1999). Conflict in marriage: Implications for working with couples. Annual Review of Psychology, 50, 47-77.

Firestone, J. M., Harris, R. J., \& Vega, W. A. (2003). The impact of gender role ideology, male expectancies, and acculturation on wife abuse. International Journal of Law and Psychiatry, 26, 549 - 564.

Fitzpatrick, M. K, Saldago, D. M., Suvak, M. K., King, L. A., \& King, D. W. (2004). Associations of gender and gender-role ideology with behavioral and attitudinal features of intimate partner aggression. Psychology of Men \& Masculinity, 5(2), 91-102.

Flannagan, C., Schulenberg, J., \& Fuligni, A. (1993). Residential setting and parentadolescent relationships during the college years. Journal of Youth and Adolescence, 22(2), 171-189.

Ford, N., Vieira, E., \& Villela, W. W. (2003). Beyond stereotypes of Brazilian male sexuality: Qualitative and quantitative findings from Brazil. Culture, Health \& Sexuality, 5, 53-69.

Fragoso, J. M., \& Kashubeck, S. (2000). Machismo, gender role conflict, and mental health in Mexican American men. Psychology of Men \& Masculinity, 1(2), 87-97.

Fry, R. (2011). Hispanic college enrollment spikes, narrowing gaps with other groups. Washington, DC: Pew Hispanic Center. 
Fry, R., \& Lopez, M. H. (2012). Hispanic student enrollments reach new highs in 2011. Washington, DC: Pew Hispanic Center.

Fuligni, A. J., Tseng, V., \& Lam, V. (1999). Attitudes toward family obligations among American adolescents with Asian, Latin American, and European backgrounds. Child Development, 70(4), 1030-1044.

Galanti, G. A. (2003). The Hispanic family and male-female relationships: An overview. Journal of Transcultural Nursing, 14, 180-185.

Gender Norms and the Role of the Extended Family. (2006). National Hispanic Healthy Marriage Initiative. Retrieved on January 15, 2014 from http://www.acf.hhs. gov/healthymarriage/pdf/Gender_Norms.pdf

Gergen, K. G. (1985). Social constructionist inquiry: Context and implications. In K. J. Gergen \& K. E. Davis (Eds.), The social construction of the person (pp. 3-18). New York: Springer-Verlag.

Glass, J., \& Owen, J. (2010). Latino fathers: The relationship among machismo, acculturation, ethnic identity, and paternal involvement. Psychology of Men \& Masculinity, 11, 251-261.

Gonzalez-Guarda, R. M., Cummings, A. M., Becerra, M., Fernandez, M. C., \& Mesa, I. (2013). Needs and preferences for the prevention of intimate partner violence among Hispanics: A community's perspective. The Journal of Primary Prevention, 34(4), 221 235.

Gonzalez-Guarda, R. M., Vasquez, E. P., Urrutia, M. T., Villarruel, A. M., \& Peragallo, N. (2011). Hispanic women's experiences with substance abuse, intimate partner violence, and risk for HIV. J Transcult Nurs 22(1), 46-54.

Greeff A. P. \& De Bruyne, T. (2000). Conflict management style and marital satisfaction. Journal of Sex \& Marital Therapy, 26, 321-334.

Halford, W. K., Sanders, M. R., \& Behrens, B. C. (2000). Repeating the errors of our parents? Family-of-origin violence and observed conflict management in engaged couples. Family Process, 39, 219-235.

Hamby, S. L. \& Sugarman, D. B. (1999). Acts of psychological aggression against a partner and their relation to physical assault and gender. Journal of Marriage and the Family, 61(4), 959-970.

Harned, M. S. (2001). Abused women or abused men? An examination of the context and outcomes of dating violence. Violence and Victims, 16(3), 269-285. 
Harris, R. J., Firestone, J. M., Vega, W. A. (2005). The interaction of country of origin, acculturation, and gender role ideology on wife abuse. Social Science Quarterly, 86(2), 463-483.

Hegarty, K., Gunn, J., Chondros, P., \& Small, R. (2004). Association between depression and abuse by partners of women attending general practice: Descriptive, cross sectional survey. BMJ, 328, 621-624.

Hines, D. A., \& Saudino, K. J. (2002). Intergenerational transmission of intimate partner violence: A behavioral genetic perspective. Trauma, Violence, \& Abuse, 3, 210-225.

Hines, D. A. \& Saudino, K. J. (2003). Gender differences in psychological, physical, and sexual aggression among college students using the revised conflict tactics scales. Violence and Victims, 18(2), 197-217.

Hofferth, S. L. (2003). Race/ethnic differences in father involvement in two-parent families: Culture, context, or economy? Journal of Family Issues, 24(2), 185-216.

Hovell, M., Sipan, C., Blumberg, El., Atkins, C., Hofsteter, R., \& Kreitner, S. (1994). Family influences on Latino and Anglo adolescents' sexual behavior. Journal of Marriage and the Family, 56, 973-986.

Howard, D. E., Beck, K., Kerr, M. H., \& Shattuck, T. (2005). Psychosocial correlates of dating violence victimization among Latino youth. Adolescence, 40(158), 319-331.

Hughes, H. M. (1988). Psychological and behavioral correlates of family violence in child witnesses and victims. American Orthopsychiatric Association, 58, 7-90.

Infante, D. A., Sabourin, T. C., Rudd, J. E., \& Shannon, E. A. (1990). Verbal aggression in violent and nonviolent marital disputes. Communication Quarterly, 38, 361-371.

Infante, D. A, Trebing, J. D, Shepherd, P. A, \& Seeds, D. E. (1984). The relationship of argumentativeness to verbal aggression. The Southern Speech Communication Journal, 50, 67-77.

Jasinski, J. L. (1998). The role of acculturation in wife assault. Hispanic Journal of Behavioral Sciences, 20(2), 175-191.

Jezl, D. R., Molidor, C. E., \& Wright, T. L. (1996). Physical, sexual and psychological abuse in high school dating relationships: Prevalence rates and self-esteem issues. Child and Adolescent Social Work Journal, 13(1), 69-87

Jouriles, E. N., Murphy, C. M., \& O'Leary, K. D. (1989). Interspousal aggression, marital discord, and child problems. Journal of Consulting and Clinical Psychology, 57, 453455. 
Kalmuss, D. (1984). The intergenerational transmission of marital aggression. Journal of Marriage and Family, 46, 11-19.

Katz, J., Moore, J. A., \& Tkachuk, S. (2007) Verbal sexual coercion and perceived victim responsibility: Mediating effects of perceived control. Sex Roles, 57(3-4), 235-247. doi:10.1007/s11199-007-9253-x

Katz, J., Washington Kuffel, S., \& Brown, F. A. (2006). Leaving a sexually coercive dating partner: A prospective application of the investment model. Psychology of Women Quarterly, 30(3), 267-275. doi:10.1111/j.1471-6402.2006.00295.x

Kelly, L., \& Radford, J. (1998). Sexual violence against women and girls: An approach to an international overview. In R. E. Dobash \& R. P. Dobash (Eds.), Rethinking violence against women (pp. 53-76). Thousand Oaks, CA: Sage.

Klevens, J. (2007). An overview of intimate partner violence among Latinos. Violence Against Women, 13, 111-122.

Kline, R. B. (1998). Principles and Practice of Structural Equation Modeling. New York: The Guilford Press.

Korbin, J. E. (1991). Cross-cultural perspectives and research directions for the $21 \mathrm{st}$ century. Child Abuse \& Neglect, 15, 67-77.

Kouros, C. D. \& Cummings, E. M. (2011). Transactional relations between marital functioning and depressive symptoms. American Journal of Orthopsychiatry, 81, 128 138.

Lefever, S., Dal, M., \& Matthíasdóttir, A. (2007) Online data collection in academic research: advantages and limitations. British Journal of Educational Technology, 38,574582.

Lehrer, J. A., Lehrer, E. L., \& Zhao, Z. (2010). Physical dating violence victimization in college women in Chile. Journal of Women's Health, 19, 893-902.

Liang, C. T. H., Salcedo, J., \& Miller, H. (2011). Perceived racism, masculinity ideologies, and gender role conflict among Latino men. Psychology of Men \& Masculinity, 12, 201-215.

Lohman, B. J., Neppl, T. K., Senia, J. M., \& Schofield, T. J. (2013). Understanding adolescent and family influences on intimate partner psychological violence during emerging adulthood and adulthood. Journal of Youth and Adolescence, 42, 500-517.

Lorenz-Blanco, E. I., Unger, J. B., Baezconde-Garbanati, L., Ritt-Olson, A., Soto, D. (2012). Acculturation, enculturation, and symptoms of depression in Hispanic youth: The 
roles of gender, Hispanic cultural values, and family functioning. Journal of Youth and Adolescence, 41, 1350-1365.

Machado, C., Caridade, S., \& Martins, C. (2009). Violence in juvenile dating relationships: Self-reported prevalence and attitudes in a Portuguese sample. Journal of Family Violence, 25(1), 43-52.

Marchand, J. F. \& Hock, E. (2000). Avoidance and attacking conflict-resolution strategies among married couples: Relations to depressive symptoms and marital satisfaction. Family Relations, 49, 201-206.

Marrs Fuchsel, C. L., Murphy, S. B., \& Dufresne, R. (2012). Domestic violence, culture, and relationship dynamics among immigrant Mexican women. Journal of Women and Social Work, 27(3), 263-274.

McGonagle, K. A., Kessler, R. C., \& Gotlib, I. H. (1992). The effects of marital disagreement style, frequency, and outcome on marital disruption. Journal of Social and Personal Relationships, 10, 385-404.

Milletich, R. J., Kelley, M. L., Doane, A. N., \& Pearson, M. R. (2010). Exposure to interparental violence and childhood physical and emotional abuse as related to physical aggression in undergraduate dating relationships. Journal of Family Violence, 25, 627637.

Moreno, C. (2007). The relationship between culture, gender, structural factors, abuse, trauma, and HIV/AIDS for Latinas. Qualitative Health Research, 17, 340-352.

Muehlenhard, C. L. \& Kimes, L. A. (1999). The Social Construction of Violence: The Case of Sexual and Domestic Violence. Personality and Social Psychology Review, 3, 234- 245.

Muñoz-Rivas, M. J., Graña, J. L., O'Leary, K. D., \& González Lozano, M. P. (2007). Aggression in adolescent dating relationships: Prevalence, justification, and health consequences. Journal of Adolescent Health, 40, 298-304.

Muñoz-Rivas, M. J., Graña, J. L., O'Leary, K. D., \& González, M. P. (2009). Prevalence and predictors of sexual aggression in dating relationships of adolescents and young adults. Psicothema, 21(2), 234-240.

Murphy, C. M. \& Blumenthal, D. R. (2000). The mediating influence of interpersonal problems on the intergenerational transmission of relationship aggression. Personal Relationships, 7, 203-218. 
Nabors, E. L. \& Jasinski, J. L. (2009). Intimate partner violence perpetration among college students: The role of gender role and gendered violence attitudes. Feminist Criminology, 4(1), 57-82.

Nelson, C. \& Tienda, M. (1985). The structuring of Hispanic ethnicity: Historical and contemporary perspectives. Ethnic and Racial Studies, 8(1), 49-74.

O'Leary, K. D. (1999). Psychological abuse: A variable deserving critical attention in domestic violence. Violence and Victims, 14, 3-23.

O’Sullivan, L. F., Meyer-Bahlburg, H., \& Watkins, B. (2001). Mother-Daughter communication about sex among urban African American and Latino families. Journal of Adolescent Research, 16, 269-292.

Ojeda, L., \& Liang, C. T. (2014). Ethnocultural and gendered determinants of coping among Mexican American adolescent men. Psychology of Men \& Masculinity, 15(3), 296-304.

Ojeda, L., \& Piña-Watson, B. (2014). Caballerismo may protect against the role of machismo on Mexican day laborers' self-esteem. Psychology of Men \& Masculinity, 15(3), 288-295.

Palazzolo, K. E., Roberto, A. J., \& Babin, E. A. (2010): The relationship between parents' verbal aggression and young adult children's intimate partner violence victimization and perpetration. Health Communication, 25(4), 357-364.

Pardo, Y., Weisfeld, C., Hill, E., \& Slatcher, R. B. (2013). Machismo and marital satisfaction in Mexican American couples. Journal of Cross-Cultural Psychology, 44(2), 299-315.

Pico-Alfonso, M. A. et al. (2006). The impact of physical, psychological, and sexual intimate male partner violence on women's mental health: Depressive symptoms, posttraumatic stress disorder, state anxiety, and suicide. Journal of Women's Health, 15, 599-611.

Portes, A. (1987). The social origins of the Cuban enclave economy of Miami. Sociological Perspectives, 30(4), 340-372.

Prospero, M. \& Vohra-Gupta, S. (2007). Gender differences in the relationship between intimate partner violence victimization and the perception of dating situations among college students. Violence and Victims, 22(4), 489-502.

Raffaelli, M., \& Ontai, L. L. (2001). "She's sixteen years old and there's boys calling over to the house": An exploratory study of sexual socialization in Latino families. Culture, Health, and Sexuality, 3, 295-310. 
Raffaelli, M., \& Suarez-al-Adam, M. (1998). Reconsidering the HIV prevention needs of Latino women in the United States. In N. L. Roth and L.K. Fullers (Eds.), Women and AIDS: Negotiating safer practices, care, and representation (pp. 7-41). New York: Haworth.

Rancer, A. S., \& Avtgis, T. A. (2006). Argumentative and Aggressive Communication: Theory, Research, and Application. Thousand Oaks: CA. Sage Publications.

Roberts, R., Phinney, J., Masse, L., Chen, Y., Roberts, C., \& Romero, A. (1999). The structure of ethnic identity in young adolescents from diverse ethnocultural groups. Journal of Early Adolescence, 19, 301-322.

Sabogal, F., Marín, G., Otero-Sabogal, R., Marín, B., \& Pérez-Stable, E. J. (1987). Hispanic familism and acculturation: What changes and what doesn't? Hispanic Journal of Behavioral Sciences, 9, 397-412.

Salis, K. L. Salwen, J., \& O'Leary, D. K. (2014). The Predictive Utility of Psychological Aggression for Intimate Partner Violence. Partner Abuse, 5, 83-97.

Salyers Bull, S. (1998). Machismo/marianismo attitudes, employment, education, and sexual behavior among women in Ecuador and the Dominican Republic. Journal of Gender, Culture and Health. 3, 1-27.

Sanderson, M., Coker, A. L., Roberts, R. E., Tortolero, S. R., \& Reininger, B. M. (2004). Acculturation, ethnic identity, and dating violence among Latino ninth-grade students. Preventative Medicine, 39, 373-383.

Schnurr, M. P., Mahatmya, D., \& Basche, R. A. (2013). The role of dominance, cyber aggression perpetration, and gender on Emerging Adults' perpetration of intimate partner violence. Psychology of Violence, 3(1), 70-83.

Schumacher, J. A. \& Leonard, K. E. (2005). Husbands' and wives' marital adjustment, verbal aggression, and physical aggression as longitudinal predictors of physical aggression in early marriage. Journal of Consulting and Clinical Psychology 73(1), 2837.

Schwartz, S. J., Pantin, H., Sullivan, S., Prado, G., \& Szapocznik, J. (2006). Nativity and years in the receiving culture as markers of acculturation in ethnic enclaves. Journal of Cross-Cultural Psychology, 37, 345-353.

Simmons, C. A., Lehman, P., \& Cobb, N. (2008). Women arrested for partner violence and substance use: An exploration of discrepancies in the literature. Journal of Interpersonal Violence, doi: 10.1177/0886260507313945. 
Skuja, K. \& Halford, W. K. (2004). Repeating the errors of our parents?: Parental violence in men's family of origin and conflict management in dating couples. Journal of Interpersonal Violence, 19, 623-638.

Smith, B. A., Thompson, S., Tomaka, J., \& Buchanan, A. C. (2005). Development of the intimate partner violence attitudes scale (IPVAS) with a predominantly Mexican American college sample. Hispanic Journal of Behavioral Sciences, 27(4), 442-454.

Smokowski, P.R. \& Bacallao, M.L. (2006). Acculturation and aggression in Latino adolescents: A structural model focusing on cultural risk factors and assets. Journal of Abnormal Child Psychology, 34(5), 657-671.

Smokowski, P. R., Rose, R. A., Bacallao, M. L. (2009). Acculturation and aggression in Latino adolescents: Modeling longitudinal trajectories from the Latino Acculturation Health Project. Journal of Child Psychiatry and Human Development, 40(4), 589-608.

Snethen, G., \& Van Puymbroeck, M. (2008). Girls and physical aggression: causes, trends, and intervention guided by social learning theory. Aggression and Violent Behavior, 13, 346-354.

Sobralske, M. C. (2006a). Health care seeking among Mexican American men. Journal of Transcultural Nursing, 17, 129-138.

Sobralske, M. C. (2006b). Machismo sustains health and illness beliefs of Mexican American men. Journal of the American Academy of Nurse Practitioners, 18, 348-350.

Stephens, D. P., \& Eaton, A. (2014). The influence of masculinity scripts on heterosexual Hispanic college men's perceptions of female-initiated sexual coercion. Psychology of Men and Masculinity, 15(4), 387-396.

Stephens, D. P., Fernandez, P. \& Richman, E. (2012). Ni pardo, ni prieto: The influence of parental skin color messaging on emerging adult Hispanic women's dating beliefs. Women \& Therapy: Special Issue on Latinas and Latin America, 35, 4-18.

Stephens, D. P. \& Thomas, T. L. (2014). Social networks influencing Hispanic women's HPV vaccine uptake decision making process. Women's Reproductive Health, 1, 120 137.

Stith, S. M. \& Farley, S. C. (1993). A predictive model of male spousal violence. Journal of Family Violence, 8(2), 183-201.

Stith, S. M., Smith, D. B., Penn, C. E., Ward, D. B., \& Tritt, D. (2004). Intimate partner physical abuse perpetration and victimization risk factors: A meta-analytic review.

Aggression and Violent Behavior, 10(1), 65-98. 
Stockdale, L., Tackett, S., \& Coyne, S. M. (2013) Sex differences in verbal aggression use in romantic relationships: a meta-analytic study and review. Journal of Aggression, Conflict and Peace Research, 5, 167-178.

Straus, M. A. (2008). Dominance and symmetry in partner violence by male and female university students in 32 nations. Children and Youth Services Review, 30, 252-275.

Straus, M. A., Hamby, S. L., Buncy-McCoy, S. \& Sugarman D. B. (1996). The revised Conflict Tactics Scale (CTS2): Development and preliminary psychometric data. Journal of Family Issues, 17, 283-316.

Straus, M. A. \& Sweet, S. (1992). Verbal/symbolic aggression in couples: Incidence rates and relationships to personal characteristics. Journal of Marriage and Family, 54, 346357.

Struckman-Johnson, C., \& Struckman-Johnson, D. (1994). Men pressured and forced into sexual experience. Archives of Sexual Behavior, 23(1), 93-114.

Struckman-Johnson, D., \& Struckman-Johnson, C. (1996). College men's reactions to hypothetical forceful sexual advances from women. In Byers E. S., \& O'Sullivan L. F. (Eds.), Sexual Coercion in Dating Relationships (pp. 93-105). New York: Haworth Press

Temple, J. R., Shorey, R. C., Tortolero, S. R., Wolfe, D. A., \& Stuart, G. L. (2013). Importance of gender and attitudes about violence in the relationship between exposure to interparental violence and the perpetration of teen dating violence. Child Abuse \& Neglect, 37(5), 343-352.

Torres, J. B. (1998). Masculinity and gender roles among Puerto Rican men: Machismo on the U.S. mainland. American Journal of Orthopsychiatry, 68(1), 16-26.

Torres, J. B., Solberg, V. S. H., \& Carlstrom, A. H. (2002). The myth of sameness among Latino men and their machismo. American Journal of Orthopsychiatry, 72, 163-181.

Ulloa, E. C., Jaycox, L. H., Marshall, G. N., Collins, R. L. (2004). Acculturation, gender stereotypes, and attitudes about dating violence among Latino youth. Violence and Victims, 19(3), 273-287.

Ulloa, E. C., Jaycox, L. H., Skinner, S. K., \& Orsburn, M. M. (2008). Attitudes about violence and dating among latino/a boys and girls. Journal of Ethnic \& Cultural Diversity in Social Work, 17(2), 157-176.

Unger, J. B., Ritt-Olson, A., Soto, D. W., Baezconde-Garbanati, L. (2009). Parent-child acculturation discrepancies as a risk factor for substance use among Hispanic adolescents in southern California. Journal of Immigrant and Minority Health, 11(3), 149-157. 
Van Doorn, M. D., Branje, S. J., \& Meeus, W. H. (2007). Longitudinal transmission of conflict resolution styles from marital relationships to adolescent-parent relationships. Journal of Family Psychology, 21, 426-434.

Villaruel, A. M. (1998). Cultural influences on the sexual attitudes, beliefs, and norms of young Latina adolescents. Journal of the Society of Pediatric Nurses, 3, 69-79.

Villegas, N, Santisteban, D., Cianelli, R., Ferrer, L., Ambrosia, T., Peragallo N., \& Lara, L. (2014). Pilot testing an internet-based STI and HIV prevention intervention with Chilean women. Journal of Nursing Scholarship, 47(2), 106-116.

Wekerle, C. \& Wolfe, D. A. (1999). Dating violence in mid-adolescence: Theory, significance, and emerging prevention initiatives. Clinical Psychology Review, 19, 435456.

Wessel, L. \& Campbell, J. C. (1997). Providing sanctuary for battered women: Nicaragua's Casas de la Mujer. Issues in Mental Health Nursing, 18, 455-476.

White, J. W. \& Koss, M. P. (1991). Courtship violence: Incidence in a national sample of higher education students. Violence and Victims, 6(4), 247-256.

White, L. (1999). Contagion in family affection: Mothers, fathers, and young adult children. Journal of Marriage and Family, 61, 284-294.

Williams, C., Richardson, D. S., Hammock, G. S. \& Janit, A. S. (2012). Perceptions of physical and psychological aggression: A review. Aggression and Violent Behavior, 17, 479-484.

Woodin, E. M. Caldeira V., \& O’Leary, D. K. (2013). Dating Aggression in Emerging Adulthood : Interactions between Relationship Processes and Individual Vulnerabilities. Journal of Social and Clinical Psychology, 32, 619-650. 
TABLES

Table 1

Participants' Nationality

\begin{tabular}{lcc}
\hline & Frequency & Percentage \\
\hline Cuban & 314 & 45.7 \\
Colombian & 75 & 10.9 \\
Puerto Rican & 50 & 7.3 \\
Venezuelan & 42 & 6.1 \\
Nicaraguan & 40 & 5.8 \\
Peruvian & 27 & 3.9 \\
Mexican & 12 & 1.7 \\
Dominican & 43 & 6.3 \\
Honduran & 17 & 2.5 \\
Argentinean & 11 & 1.6 \\
Ecuadorian & 8 & 1.2 \\
Chilean & 6 & 0.9 \\
Panamanian & 4 & 0.6 \\
Brazilian & 7 & 1.0 \\
Costa Rican & 4 & 0.6 \\
Uruguayan & 2 & 0.3 \\
Portuguese & 1 & 0.1 \\
Guatemalan & 7 & 1.0 \\
Other & 17 & 2.5 \\
\hline
\end{tabular}


Table 2

Participants' American Generation

Frequency Percentage

I was not born in the US

223

32.5

First generation American

312

45.4

Second Generation American

111

16.2

Third (or more) generation American

41

6.0 
Table 3

Mother Figure

\begin{tabular}{lcc}
\hline & Frequency & Percentage \\
\hline Biological Mother & 680 & 99 \\
Adoptive Mother & 3 & 0.4 \\
Stepmother & 1 & 0.1 \\
Grandmother & 1 & 0.1 \\
Aunt & 2 & 0.3 \\
\hline
\end{tabular}


Table 4

Father Figure

\begin{tabular}{lcc}
\hline & Frequency & Percentage \\
\hline Biological Father & 617 & 89.8 \\
Adoptive Father & 10 & 1.5 \\
Stepfather & 54 & 7.9 \\
Grandfather & 5 & 0.7 \\
Uncle & 1 & 0.1 \\
\hline
\end{tabular}


Table 5

Participants' Living Situation

\begin{tabular}{lcc}
\hline & Frequency & Percentage \\
\hline Two parents & 382 & 55.6 \\
Just my mother & 140 & 20.4 \\
Just my father & 14 & 2.0 \\
Aunt or Uncle & 4 & 0.6 \\
Grandparent(s) & 8 & 1.2 \\
Roommate(s) & 56 & 8.2 \\
Alone & 14 & 2.0 \\
\hline
\end{tabular}


Table 6

Mother's Highest Level of Education Achieved Frequency

Less than high school

High school/GED 34

Some college

155

168

96

151

59

Percentage

Associate's degree

Bachelor's degree

4.9

22.6

24.5

14.0

22.0

Master's degree

8.6 
Table 7

Father's Highest Level of Education Achieved

\begin{tabular}{lcc}
\hline & Frequency & Percentage \\
\hline Less than high school & 58 & 8.4 \\
High school/GED & 162 & 23.6 \\
Some college & 150 & 21.8 \\
Associate's degree & 72 & 10.5 \\
Bachelor's degree & 140 & 20.4 \\
Master's degree & 65 & 9.5 \\
\hline
\end{tabular}


Table 8

Participant's Class Level (Based on Number of Credits Obtained)

\begin{tabular}{lcc}
\hline & Frequency & Percentage \\
\hline Freshman (0-29) & 97 & 14.1 \\
Sophomore (30-59) & 98 & 14.3 \\
Junior (60-89) & 256 & 37.3 \\
Senior (90-120) & 204 & 29.7 \\
Senior Plus (more than 120) & 32 & 4.7 \\
\hline
\end{tabular}


Table 9

Participant's Relationship Status at the Time of Survey Completion

\begin{tabular}{lcc}
\hline & Frequency & Percentage \\
\hline Not dating anyone & 138 & 20.1 \\
Dating one person & 200 & 29.1 \\
Dating two people & 3 & 0.4 \\
Dating several people & 9 & 1.3 \\
I am in a committed relationship with one person & 321 & 46.7 \\
I am in a committed relationship with two or more people & 1 & 0.1 \\
\hline
\end{tabular}


Table 10

Participant's Number of Past-Year Relationships

\begin{tabular}{lcc}
\hline & Frequency & Percentage \\
\hline One & 641 & 93.3 \\
Two & 42 & 6.1 \\
Three & 0 & 0 \\
Four or more & 3 & 0.4 \\
\hline
\end{tabular}


Table 11

Study 1 Intercorrelation of Variables

\begin{tabular}{|c|c|c|c|c|c|}
\hline Variable & 2 & 3 & 4 & 5 & 6 \\
\hline 1. Mother to Participant Psych Aggression & .336 & .035 & -.091 & .008 & .195 \\
\hline 2. Father to Participant Psych Aggression & --- & .019 & -.046 & -.001 & .235 \\
\hline 3. Machismo Beliefs & & --- & .149 & .155 & .070 \\
\hline 4. Caballerismo Beliefs & & & --- & .176 & -.084 \\
\hline 5. Attitudes Endorsing Boyfriend's & & & & --- & .029 \\
\hline
\end{tabular}


Table 12

Study 2 Intercorrelation of Variables

\begin{tabular}{lcccc}
\hline \multicolumn{1}{c}{ Variable } & 2 & 3 & 4 & 5 \\
\hline 1. Mother to Participant Psych Aggression & .336 & -.012 & -.019 & .240 \\
2. Father to Participant Psych Aggression & --- & -.075 & .043 & .208 \\
3. Marianismo Beliefs & & --- & .136 & -.071 \\
4. Attitudes Endorsing Own Perpetration & & & --- & .164 \\
5. Participant to Boyfriend Psych Aggression & & & ---
\end{tabular}


Table 13

Study 1 Tolerance Levels and Variance Inflation Factors (VIF)

\begin{tabular}{lcc}
\hline \multicolumn{1}{c}{ Variable } & Tolerance & VIF \\
\hline Mother to Participant Psych Aggression & .879 & 1.137 \\
Father to Participant Psych Aggression & .887 & 1.128 \\
Machismo Beliefs & .959 & 1.043 \\
Caballerismo Beliefs & .944 & 1.059 \\
Attitudes Endorsing Boyfriend's & .952 & 1.051 \\
Perpetration & & \\
\hline
\end{tabular}


Table 14

Study 2 Tolerance Levels and Variance Inflation Factors (VIF)

\begin{tabular}{lcc}
\hline \multicolumn{1}{c}{ Variable } & Tolerance & VIF \\
\hline Mother to Participant Psych Aggression & .886 & 1.129 \\
Father to Participant Psych Aggression & .879 & 1.138 \\
Marianismo Beliefs & .975 & 1.026 \\
Attitudes Endorsing Own Perpetration & .977 & 1.023 \\
\hline
\end{tabular}


Table 15

Study 1 Means and Standard Deviations (SD)

\begin{tabular}{lcc}
\hline \multicolumn{1}{c}{ Variable } & Mean & SD \\
\hline Mother to Participant Psych Aggression & 6.649 & 7.145 \\
Father to Participant Psych Aggression & 2.710 & 4.308 \\
Machismo Beliefs & 20.207 & 8.160 \\
Caballerismo Beliefs & 25.969 & 18.323 \\
Attitudes Endorsing Boyfriend's & 7.661 & 2.403 \\
Perpetration & & \\
Boyfriend to Participant Psych & 4.788 & 6.513 \\
Aggression & & \\
\hline
\end{tabular}


Table 16

Intimate Partner Violence Attitudes Scale: Abuse Subscale (Victimization)

\begin{tabular}{|c|c|c|}
\hline & Frequency & Percent \\
\hline \multicolumn{3}{|c|}{ As long as my partner doesn't hurt me, “threats" are excused } \\
\hline Strongly Disagree & 477 & 69.4 \\
\hline Disagree & 173 & 25.2 \\
\hline Agree & 32 & 4.7 \\
\hline Strongly Agree & 5 & 0.7 \\
\hline \multicolumn{3}{|c|}{ I don't mind my partner doing something just to make me jealous } \\
\hline Strongly Disagree & 471 & 68.6 \\
\hline Disagree & 176 & 25.6 \\
\hline Agree & 34 & 4.9 \\
\hline Strongly Agree & 6 & 0.9 \\
\hline \multicolumn{3}{|c|}{ It is no big deal if my partner insults me in front of others } \\
\hline Strongly Disagree & 548 & 79.8 \\
\hline Disagree & 106 & 15.4 \\
\hline Agree & 26 & 3.8 \\
\hline Strongly Agree & 7 & 1.0 \\
\hline \multicolumn{3}{|c|}{ It is okay for me to accept blame for my partner doing bad things } \\
\hline Strongly Disagree & 495 & 72.1 \\
\hline Disagree & 156 & 22.7 \\
\hline Agree & 29 & 4.2 \\
\hline Strongly Agree & 7 & 1.0 \\
\hline \multicolumn{3}{|c|}{ It is not acceptable for my partner to bring up something from the past to hurt me } \\
\hline Strongly Disagree & 182 & 26.5 \\
\hline Disagree & 96 & 14.0 \\
\hline Agree & 162 & 23.6 \\
\hline Strongly Agree & 247 & 36.0 \\
\hline
\end{tabular}


Table 17

Machismo Scale (Questions Assessing Machismo Beliefs)

\begin{tabular}{|c|c|c|}
\hline & Frequency & Percent \\
\hline \multicolumn{3}{|l|}{ Men are superior to women } \\
\hline Strongly Disagree & 531 & 77.3 \\
\hline Disagree & 78 & 11.4 \\
\hline Somewhat Disagree & 18 & 2.6 \\
\hline Neither Agree nor Disagree & 34 & 4.9 \\
\hline Somewhat Agree & 14 & 2.0 \\
\hline Agree & 6 & 0.9 \\
\hline Strongly Agree & 6 & 0.9 \\
\hline \multicolumn{3}{|l|}{ In a family, a father's wish is law } \\
\hline Strongly Disagree & 420 & 61.1 \\
\hline Disagree & 140 & 20.4 \\
\hline Somewhat Disagree & 38 & 5.5 \\
\hline Neither Agree nor Disagree & 39 & 5.7 \\
\hline Somewhat Agree & 34 & 4.9 \\
\hline Agree & 9 & 1.3 \\
\hline Strongly Agree & 7 & 1.0 \\
\hline \multicolumn{3}{|c|}{ The birth of a male child is more important than the birth of a female child } \\
\hline Strongly Disagree & 562 & 81.8 \\
\hline Disagree & 86 & 12.5 \\
\hline Somewhat Disagree & 7 & 1.0 \\
\hline Neither Agree nor Disagree & 18 & 2.6 \\
\hline Somewhat Agree & 8 & 1.2 \\
\hline Agree & 3 & 0.4 \\
\hline Strongly Agree & 3 & 0.4 \\
\hline \multicolumn{3}{|c|}{ It is important not to be the weakest man in a group } \\
\hline Strongly Disagree & 296 & 43.1 \\
\hline Disagree & 107 & 15.6 \\
\hline Somewhat Disagree & 51 & 7.4 \\
\hline Neither Agree nor Disagree & 93 & 13.5 \\
\hline Somewhat Agree & 80 & 11.6 \\
\hline Agree & 43 & 6.3 \\
\hline Strongly Agree & 17 & 2.5 \\
\hline
\end{tabular}


Table 17 (Continued)

Machismo Scale (Questions Assessing Machismo Beliefs)

\begin{tabular}{|c|c|c|}
\hline & Frequency & Percent \\
\hline \multicolumn{3}{|c|}{ Real men never let down their guard } \\
\hline Strongly Disagree & 341 & 49.6 \\
\hline Disagree & 122 & 17.8 \\
\hline Somewhat Disagree & 64 & 9.3 \\
\hline Neither Agree nor Disagree & 75 & 10.9 \\
\hline Somewhat Agree & 43 & 6.3 \\
\hline Agree & 29 & 4.2 \\
\hline Strongly Agree & 13 & 1.9 \\
\hline \multicolumn{3}{|c|}{ It would be shameful for a man to cry in front of his children } \\
\hline Strongly Disagree & 438 & 63.8 \\
\hline Disagree & 153 & 22.3 \\
\hline Somewhat Disagree & 40 & 5.8 \\
\hline Neither Agree nor Disagree & 27 & 3.9 \\
\hline Somewhat Agree & 20 & 2.9 \\
\hline Agree & 6 & 0.9 \\
\hline Strongly Agree & 3 & 0.4 \\
\hline \multicolumn{3}{|c|}{ A man should be in control of his wife } \\
\hline Strongly Disagree & 478 & 69.6 \\
\hline Disagree & 108 & 15.7 \\
\hline Somewhat Disagree & 41 & 6.0 \\
\hline Neither Agree nor Disagree & 31 & 4.5 \\
\hline Somewhat Agree & 18 & 2.6 \\
\hline Agree & 6 & 0.9 \\
\hline Strongly Agree & 5 & 0.7 \\
\hline \multicolumn{3}{|c|}{ It is necessary to fight when challenged } \\
\hline Strongly Disagree & 236 & 34.4 \\
\hline Disagree & 164 & 23.9 \\
\hline Somewhat Disagree & 69 & 10.0 \\
\hline Neither Agree nor Disagree & 81 & 11.8 \\
\hline Somewhat Agree & 89 & 13.0 \\
\hline Agree & 32 & 4.7 \\
\hline Strongly Agree & 16 & 2.3 \\
\hline
\end{tabular}


Table 17 (Continued)

Machismo Scale (Questions Assessing Machismo Beliefs)

\begin{tabular}{lcc}
\hline & Frequency & Percent \\
\hline It is important for women to be beautiful & & \\
Strongly Disagree & 133 & 19.4 \\
Disagree & 99 & 14.4 \\
Somewhat Disagree & 61 & 8.9 \\
Neither Agree nor Disagree & 149 & 21.7 \\
Somewhat Agree & 126 & 18.3 \\
Agree & 75 & 10.9 \\
Strongly Agree & 44 & 6.4 \\
The bills (electric, phone, etc.) should be in the man's name & & \\
Strongly Disagree & 272 & 39.6 \\
Disagree & 159 & 23.1 \\
Somewhat Disagree & 61 & 8.9 \\
Neither Agree nor Disagree & 138 & 20.1 \\
Somewhat Agree & 31 & 4.5 \\
Agree & 14 & 2.0 \\
Strongly Agree & 12 & 1.7 \\
\hline
\end{tabular}


Table 18

Machismo Scale (Questions Assessing Caballerismo Beliefs)

\begin{tabular}{|c|c|c|}
\hline & Frequency & Percent \\
\hline \multicolumn{3}{|c|}{ Men must display good manners in public } \\
\hline Strongly Disagree & 18 & 2.6 \\
\hline Disagree & 8 & 1.2 \\
\hline Somewhat Disagree & 7 & 1.0 \\
\hline Neither Agree nor Disagree & 35 & 5.1 \\
\hline Somewhat Agree & 71 & 10.3 \\
\hline Agree & 230 & 33.5 \\
\hline Strongly Agree & 318 & 46.3 \\
\hline \multicolumn{3}{|c|}{ Men should be affectionate with their children } \\
\hline Strongly Disagree & 10 & 1.5 \\
\hline Disagree & 4 & 0.6 \\
\hline Somewhat Disagree & 4 & 0.6 \\
\hline Neither Agree nor Disagree & 17 & 2.5 \\
\hline Somewhat Agree & 27 & 3.9 \\
\hline Agree & 155 & 22.6 \\
\hline Strongly Agree & 470 & 68.4 \\
\hline \multicolumn{3}{|l|}{ Men should respect their elders } \\
\hline Strongly Disagree & 6 & 0.9 \\
\hline Disagree & 2 & 0.3 \\
\hline Somewhat Disagree & 1 & 0.1 \\
\hline Neither Agree nor Disagree & 20 & 2.9 \\
\hline Somewhat Agree & 27 & 3.9 \\
\hline Agree & 171 & 24.9 \\
\hline Strongly Agree & 460 & 67.0 \\
\hline \multicolumn{3}{|c|}{ A woman is expected to be loyal to her husband } \\
\hline Strongly Disagree & 14 & 2.0 \\
\hline Disagree & 4 & 0.6 \\
\hline Somewhat Disagree & 5 & 0.7 \\
\hline Neither Agree nor Disagree & 54 & 7.9 \\
\hline Somewhat Agree & 60 & 8.7 \\
\hline Agree & 206 & 30.0 \\
\hline Strongly Agree & 344 & 50.1 \\
\hline
\end{tabular}


Table 18 (Continued)

Machismo Scale (Questions Assessing Caballerismo Beliefs)

\begin{tabular}{|c|c|c|}
\hline & Frequency & Percent \\
\hline \multicolumn{3}{|c|}{ Men must exhibit fairness in all situations } \\
\hline Strongly Disagree & 11 & 1.6 \\
\hline Disagree & 4 & 0.6 \\
\hline Somewhat Disagree & 10 & 1.5 \\
\hline Neither Agree nor Disagree & 52 & 7.6 \\
\hline Somewhat Agree & 64 & 9.3 \\
\hline Agree & 214 & 31.1 \\
\hline Strongly Agree & 332 & 48.3 \\
\hline \multicolumn{3}{|c|}{ Men should be willing to fight to defend their family } \\
\hline Strongly Disagree & 11 & 1.6 \\
\hline Disagree & 4 & 0.6 \\
\hline Somewhat Disagree & 10 & 1.5 \\
\hline Neither Agree nor Disagree & 57 & 8.3 \\
\hline Somewhat Agree & 118 & 17.2 \\
\hline Agree & 199 & 29.0 \\
\hline Strongly Agree & 288 & 41.9 \\
\hline \multicolumn{3}{|c|}{ The family is more important than the individual } \\
\hline Strongly Disagree & 21 & 3.1 \\
\hline Disagree & 20 & 2.9 \\
\hline Somewhat Disagree & 26 & 3.8 \\
\hline Neither Agree nor Disagree & 135 & 19.7 \\
\hline Somewhat Agree & 119 & 17.3 \\
\hline Agree & 166 & 24.2 \\
\hline Strongly Agree & 200 & 29.1 \\
\hline \multicolumn{3}{|c|}{ Men hold their mothers in high regard } \\
\hline Strongly Disagree & 11 & 1.6 \\
\hline Disagree & 1 & 0.1 \\
\hline Somewhat Disagree & 7 & 1.0 \\
\hline Neither Agree nor Disagree & 76 & 11.1 \\
\hline Somewhat Agree & 106 & 15.4 \\
\hline Agree & 241 & 35.1 \\
\hline Strongly Agree & 245 & 35.7 \\
\hline
\end{tabular}


Table 18 (Continued)

Machismo Scale (Questions Assessing Caballerismo Beliefs)

\begin{tabular}{lcc}
\hline & Frequency & Percent \\
\hline A real man does not brag about sex & 15 & \\
Strongly Disagree & 6 & 2.2 \\
Disagree & 9 & 0.9 \\
Somewhat Disagree & 77 & 1.3 \\
Neither Agree nor Disagree & 51 & 11.2 \\
Somewhat Agree & 182 & 7.4 \\
Agree & 347 & 26.5 \\
Strongly Agree & & 50.5 \\
Men want their children to have better lives than themselves & 6 & \\
Strongly Disagree & 3 & 0.9 \\
Disagree & 1 & 0.4 \\
Somewhat Disagree & 37 & 0.1 \\
Neither Agree nor Disagree & 35 & 5.4 \\
Somewhat Agree & 192 & 5.1 \\
Agree & 413 & 27.9 \\
Strongly Agree & & 60.1 \\
\hline
\end{tabular}


Table 19

Conflict Tactics Scale 2 (Mother's Use of Psychological Aggression toward Participant)

\begin{tabular}{|c|c|c|}
\hline & Frequency & Percent \\
\hline \multicolumn{3}{|l|}{ Mother insulted or swore at you } \\
\hline Once that year & 57 & 8.3 \\
\hline Twice that year & 75 & 10.9 \\
\hline $3-5$ times that year & 80 & 11.6 \\
\hline $6-10$ times that year & 54 & 7.9 \\
\hline $11-20$ times that year & 35 & 5.1 \\
\hline More than 20 times that year & 62 & 9.0 \\
\hline This did not happen during that year & 324 & 47.2 \\
\hline \multicolumn{3}{|l|}{ Mother shouted or yelled at you } \\
\hline Once that year & 27 & 3.9 \\
\hline Twice that year & 34 & 4.9 \\
\hline $3-5$ times that year & 70 & 10.2 \\
\hline $6-10$ times that year & 77 & 11.2 \\
\hline $11-20$ times that year & 55 & 8.0 \\
\hline More than 20 times that year & 98 & 14.3 \\
\hline This did not happen during that year & 326 & 47.5 \\
\hline \multicolumn{3}{|l|}{ Mother stomped out of the room } \\
\hline Once that year & 36 & 5.2 \\
\hline Twice that year & 43 & 6.3 \\
\hline $3-5$ times that year & 84 & 12.2 \\
\hline $6-10$ times that year & 44 & 6.4 \\
\hline 11-20 times that year & 24 & 3.5 \\
\hline More than 20 times that year & 21 & 3.1 \\
\hline This did not happen during that year & 435 & 63.3 \\
\hline \multicolumn{3}{|c|}{ Mother Threatened to hit or throw something at you } \\
\hline Once that year & 20 & 2.9 \\
\hline Twice that year & 28 & 4.1 \\
\hline 3-5 times that year & 25 & 3.6 \\
\hline $6-10$ times that year & 10 & 1.5 \\
\hline 11-20 times that year & 9 & 1.3 \\
\hline More than 20 times that year & 11 & 1.6 \\
\hline This did not happen during that year & 584 & 85.0 \\
\hline
\end{tabular}


Table 19 (Continued)

Conflict Tactics Scale 2 (Mother's Use of Psychological Aggression toward Participant)

\begin{tabular}{lcc}
\hline & Frequency & Percent \\
\hline Mother destroyed something belonging to you & 18 & 2.6 \\
Once that year & 6 & 0.9 \\
Twice that year & 10 & 1.5 \\
3-5 times that year & 4 & 0.6 \\
6-10 times that year & 1 & 0.1 \\
11-20 times that year & 1 & 0.1 \\
More than 20 times that year & 647 & 94.2 \\
This did not happen during that year & & \\
Mother did something to spite you & 28 & 4.1 \\
Once that year & 20 & 2.9 \\
Twice that year & 36 & 5.2 \\
3-5 times that year & 10 & 1.5 \\
6-10 times that year & 7 & 1.0 \\
11-20 times that year & 7 & 1.0 \\
More than 20 times that year & 579 & 84.3 \\
This did not happen during that year & & \\
Mother called you fat or ugly & 30 & 4.8 \\
Once that year & 22 & 3.4 \\
Twice that year & 22 & 3.2 \\
3-5 times that year & 25 & 3.2 \\
6-10 times that year & 10 & 3.6 \\
11-20 times that year & 19 & \\
More than 20 times that year & 59 & \\
This did not happen during that year & & \\
\hline
\end{tabular}


Table 20

Conflict Tactics Scale 2 (Father's Use of Psychological Aggression toward Participant)

\begin{tabular}{|c|c|c|}
\hline & Frequency & Percent \\
\hline \multicolumn{3}{|l|}{ Father insulted or swore at you } \\
\hline Once that year & 33 & 4.8 \\
\hline Twice that year & 35 & 5.1 \\
\hline $3-5$ times that year & 36 & 5.2 \\
\hline $6-10$ times that year & 21 & 3.1 \\
\hline $11-20$ times that year & 14 & 2.0 \\
\hline More than 20 times that year & 15 & 2.2 \\
\hline This did not happen during that year & 533 & 77.6 \\
\hline \multicolumn{3}{|l|}{ Father shouted or yelled at you } \\
\hline Once that year & 33 & 4.8 \\
\hline Twice that year & 39 & 5.7 \\
\hline $3-5$ times that year & 49 & 7.1 \\
\hline $6-10$ times that year & 39 & 5.7 \\
\hline $11-20$ times that year & 21 & 3.1 \\
\hline More than 20 times that year & 29 & 4.2 \\
\hline This did not happen during that year & 477 & 69.4 \\
\hline \multicolumn{3}{|l|}{ Father stomped out of the room } \\
\hline Once that year & 7 & 1.0 \\
\hline Twice that year & 13 & 1.9 \\
\hline $3-5$ times that year & 4 & 0.6 \\
\hline $6-10$ times that year & 7 & 1.0 \\
\hline $11-20$ times that year & 2 & 0.3 \\
\hline More than 20 times that year & 1 & 0.1 \\
\hline This did not happen during that year & 653 & 95.1 \\
\hline \multicolumn{3}{|c|}{ Father Threatened to hit or throw something at you } \\
\hline Once that year & 12 & 1.7 \\
\hline Twice that year & 8 & 1.2 \\
\hline 3-5 times that year & 6 & 0.9 \\
\hline $6-10$ times that year & 1 & 0.1 \\
\hline $11-20$ times that year & 0 & 0.0 \\
\hline More than 20 times that year & 1 & 0.1 \\
\hline This did not happen during that year & 659 & 95.9 \\
\hline
\end{tabular}


Table 20 (Continued)

Conflict Tactics Scale 2 (Father's Use of Psychological Aggression toward Participant)

\begin{tabular}{lcc}
\hline & Frequency & Percent \\
\hline Father destroyed something belonging to you & 7 & 1.0 \\
Once that year & 5 & 0.7 \\
Twice that year & 1 & 0.1 \\
3-5 times that year & 0 & 0.0 \\
6-10 times that year & 0 & 0.0 \\
11-20 times that year & 0 & 0.0 \\
More than 20 times that year & 674 & 98.1 \\
This did not happen during that year & & \\
Father did something to spite you & 7 & 1.0 \\
Once that year & 13 & 1.9 \\
Twice that year & 4 & 0.6 \\
3-5 times that year & 7 & 1.0 \\
6-10 times that year & 2 & 0.3 \\
11-20 times that year & 1 & 0.1 \\
More than 20 times that year & 653 & 95.1 \\
This did not happen during that year & & \\
Father called you fat or ugly & 16 & 2.3 \\
Once that year & 10 & 1.5 \\
Twice that year & 18 & 2.6 \\
3-5 times that year & 1 & 0.1 \\
6-10 times that year & 3 & 0.4 \\
11-20 times that year & 2 & \\
More than 20 times that year & & \\
This did not happen during that year & & \\
\hline
\end{tabular}


Table 21

Conflict Tactics Scale 2 (Boyfriend's Use of Psychological Aggression toward Participant)

\begin{tabular}{|c|c|c|}
\hline & Frequency & Percent \\
\hline \multicolumn{3}{|l|}{ My boyfriend insulted or swore at me } \\
\hline Once that year & 54 & 7.9 \\
\hline Twice that year & 63 & 9.2 \\
\hline 3-5 times that year & 53 & 7.7 \\
\hline $6-10$ times that year & 31 & 4.5 \\
\hline $11-20$ times that year & 24 & 3.5 \\
\hline More than 20 times that year & 24 & 3.5 \\
\hline This did not happen during that year & 438 & 63.8 \\
\hline \multicolumn{3}{|l|}{ My boyfriend shouted or yelled at me } \\
\hline Once that year & 61 & 8.9 \\
\hline Twice that year & 51 & 7.4 \\
\hline $3-5$ times that year & 76 & 11.1 \\
\hline $6-10$ times that year & 48 & 7.0 \\
\hline $11-20$ times that year & 27 & 3.9 \\
\hline More than 20 times that year & 43 & 6.3 \\
\hline This did not happen during that year & 381 & 55.5 \\
\hline \multicolumn{3}{|l|}{ My boyfriend stomped out of the room } \\
\hline Once that year & 64 & 9.3 \\
\hline Twice that year & 65 & 9.5 \\
\hline 3-5 times that year & 79 & 11.5 \\
\hline $6-10$ times that year & 31 & 4.5 \\
\hline $11-20$ times that year & 17 & 2.5 \\
\hline More than 20 times that year & 20 & 2.9 \\
\hline This did not happen during that year & 411 & 59.8 \\
\hline \multicolumn{3}{|c|}{ My boyfriend threatened to hit or throw something at me } \\
\hline Once that year & 3 & 0.4 \\
\hline Twice that year & 5 & 0.7 \\
\hline 3-5 times that year & 5 & 0.7 \\
\hline $6-10$ times that year & 0 & 0 \\
\hline $11-20$ times that year & 2 & 0.3 \\
\hline More than 20 times that year & 2 & 0.3 \\
\hline This did not happen during that year & 670 & 97.5 \\
\hline
\end{tabular}


Table 21 (Continued)

Conflict Tactics Scale 2 (Boyfriend's Use of Psychological Aggression toward Participant)

\begin{tabular}{|c|c|c|}
\hline & Frequency & Percent \\
\hline \multicolumn{3}{|c|}{ My boyfriend destroyed something belonging to me } \\
\hline Once that year & 16 & 2.3 \\
\hline Twice that year & 12 & 1.7 \\
\hline 3-5 times that year & 3 & 0.4 \\
\hline 6-10 times that year & 0 & 0 \\
\hline 11-20 times that year & 1 & 0.1 \\
\hline More than 20 times that year & 1 & 0.1 \\
\hline This did not happen during that year & 654 & 95.2 \\
\hline \multicolumn{3}{|l|}{ My boyfriend did something to spite me } \\
\hline Once that year & 29 & 4.2 \\
\hline Twice that year & 51 & 7.4 \\
\hline 3-5 times that year & 40 & 5.8 \\
\hline $6-10$ times that year & 16 & 2.3 \\
\hline $11-20$ times that year & 5 & 0.7 \\
\hline More than 20 times that year & 10 & 1.5 \\
\hline This did not happen during that year & 536 & 78.0 \\
\hline \multicolumn{3}{|l|}{ My boyfriend called me fat or ugly } \\
\hline Once that year & 17 & 2.5 \\
\hline Twice that year & 13 & 1.9 \\
\hline $3-5$ times that year & 16 & 2.3 \\
\hline 6-10 times that year & 5 & 0.7 \\
\hline 11-20 times that year & 2 & 0.3 \\
\hline More than 20 times that year & 2 & 0.3 \\
\hline This did not happen during that year & 632 & 92.0 \\
\hline \multicolumn{3}{|c|}{ My boyfriend accused me of being a lousy lover } \\
\hline Once that year & 26 & 3.8 \\
\hline Twice that year & 19 & 2.8 \\
\hline $3-5$ times that year & 14 & 2.0 \\
\hline 6-10 times that year & 4 & 0.6 \\
\hline 11-20 times that year & 5 & 0.7 \\
\hline More than 20 times that year & 6 & 0.9 \\
\hline This did not happen during that year & 613 & 89.2 \\
\hline
\end{tabular}


Table 22

Study 2 Means and Standard Deviations (SD)

\begin{tabular}{lcc}
\hline \multicolumn{1}{c}{ Variable } & Mean & SD \\
\hline Mother to Participant Psych Aggression & 6.649 & 7.145 \\
Father to Participant Psych Aggression & 2.710 & 4.308 \\
Marianismo Beliefs & 52.396 & 10.006 \\
Attitudes Endorsing Own Perpetration & 10.862 & 3.351 \\
Participant to Boyfriend Psych Aggression & 6.667 & 7.342 \\
\hline
\end{tabular}


Table 23

Intimate Partner Violence Attitudes Scale: Abuse Subscale (Perpetration)

\begin{tabular}{|c|c|c|}
\hline & Frequency & Percent \\
\hline \multicolumn{3}{|c|}{ Threatening a partner is okay as long as I don't hurt him or her } \\
\hline Strongly Disagree & 449 & 65.4 \\
\hline Disagree & 201 & 29.3 \\
\hline Agree & 27 & 3.9 \\
\hline Strongly Agree & 10 & 1.5 \\
\hline \multicolumn{3}{|c|}{$\begin{array}{l}\text { During a heated argument, it is okay for me to bring up something from my partner's } \\
\text { past to hurt him or her }\end{array}$} \\
\hline Strongly Disagree & 362 & 52.7 \\
\hline Disagree & 265 & 38.6 \\
\hline Agree & 58 & 8.4 \\
\hline Strongly Agree & 2 & 0.3 \\
\hline \multicolumn{3}{|c|}{$\begin{array}{l}\text { During a heated argument it is okay for me to say something to hurt my partner on } \\
\text { purpose }\end{array}$} \\
\hline Strongly Disagree & 419 & 61.0 \\
\hline Disagree & 224 & 32.6 \\
\hline Agree & 39 & 5.7 \\
\hline Strongly Agree & 5 & 0.7 \\
\hline \multicolumn{3}{|c|}{ I think it helps our relationship for me to make my partner jealous } \\
\hline Strongly Disagree & 398 & 57.9 \\
\hline Disagree & 231 & 33.6 \\
\hline Agree & 53 & 7.7 \\
\hline Strongly Agree & 5 & 0.7 \\
\hline \multicolumn{3}{|c|}{ My partner is egotistical so I think it's okay to "put down" my partner's looks } \\
\hline Strongly Disagree & 445 & 64.8 \\
\hline Disagree & 205 & 29.8 \\
\hline Agree & 34 & 4.9 \\
\hline Strongly Agree & 3 & 0.4 \\
\hline \multicolumn{3}{|c|}{ It is okay for me to blame my partner when I do bad things } \\
\hline Strongly Disagree & 496 & 72.2 \\
\hline Disagree & 157 & 22.9 \\
\hline Agree & 28 & 4.1 \\
\hline Strongly Agree & 6 & 0.9 \\
\hline \multicolumn{3}{|c|}{ It is not appropriate to insult my partner in front of others (reversed) } \\
\hline Strongly Disagree & 177 & 25.8 \\
\hline Disagree & 75 & 10.9 \\
\hline Agree & 118 & 17.2 \\
\hline Strongly Agree & 317 & 46.1 \\
\hline
\end{tabular}


Table 24

\section{Marianismo Beliefs}

\begin{tabular}{|c|c|c|}
\hline A Latina... & Frequency & Percent \\
\hline \multicolumn{3}{|c|}{ must be a source of strength for her family } \\
\hline Strongly Disagree & 13 & 1.9 \\
\hline Disagree & 61 & 8.9 \\
\hline Agree & 416 & 60.6 \\
\hline Strongly Agree & 197 & 28.7 \\
\hline \multicolumn{3}{|c|}{ is considered the main source of strength of her family } \\
\hline Strongly Disagree & 32 & 4.7 \\
\hline Disagree & 239 & 34.8 \\
\hline Agree & 323 & 47.0 \\
\hline Strongly Agree & 93 & 13.5 \\
\hline \multicolumn{3}{|c|}{ mother must keep the family unified } \\
\hline Strongly Disagree & 18 & 2.6 \\
\hline Disagree & 89 & 13.0 \\
\hline Agree & 395 & 57.5 \\
\hline Strongly Agree & 185 & 26.9 \\
\hline \multicolumn{3}{|c|}{ should teach her children to be loyal to the family } \\
\hline Strongly Disagree & 7 & 1.0 \\
\hline Disagree & 33 & 4.8 \\
\hline Agree & 366 & 53.3 \\
\hline Strongly Agree & 281 & 40.9 \\
\hline \multicolumn{3}{|c|}{ should do things that make her family happy } \\
\hline Strongly Disagree & 15 & 2.2 \\
\hline Disagree & 60 & 8.7 \\
\hline Agree & 375 & 54.6 \\
\hline Strongly Agree & 237 & 34.5 \\
\hline \multicolumn{3}{|c|}{ should (should have) remain(ed) a virgin until marriage } \\
\hline Strongly Disagree & 211 & 30.7 \\
\hline Disagree & 321 & 46.7 \\
\hline Agree & 107 & 15.6 \\
\hline Strongly Agree & 48 & 7.0 \\
\hline \multicolumn{3}{|c|}{ should wait until after marriage to have children } \\
\hline Strongly Disagree & 61 & 8.9 \\
\hline Disagree & 159 & 23.1 \\
\hline Agree & 305 & 44.4 \\
\hline Strongly Agree & 162 & 23.6 \\
\hline
\end{tabular}


Table 24 (Continued)

Marianismo Beliefs

\begin{tabular}{|c|c|c|}
\hline A Latina... & Frequency & Percent \\
\hline \multicolumn{3}{|l|}{ should be pure } \\
\hline Strongly Disagree & 109 & 15.9 \\
\hline Disagree & 264 & 38.4 \\
\hline Agree & 255 & 37.1 \\
\hline Strongly Agree & 59 & 8.6 \\
\hline \multicolumn{3}{|c|}{ should adopt the values taught by her religion } \\
\hline Strongly Disagree & 103 & 15.0 \\
\hline Disagree & 226 & 32.9 \\
\hline Agree & 281 & 40.9 \\
\hline Strongly Agree & 77 & 11.2 \\
\hline \multicolumn{3}{|c|}{ should be faithful to her partner } \\
\hline Strongly Disagree & 7 & 1.0 \\
\hline Disagree & 16 & 2.3 \\
\hline Agree & 233 & 33.9 \\
\hline Strongly Agree & 431 & 62.7 \\
\hline \multicolumn{3}{|c|}{ should satisfy her partner's sexual needs without argument } \\
\hline Strongly Disagree & 221 & 32.2 \\
\hline Disagree & 305 & 44.4 \\
\hline Agree & 126 & 18.3 \\
\hline Strongly Agree & 35 & 5.1 \\
\hline \multicolumn{3}{|c|}{ should not speak out against men } \\
\hline Strongly Disagree & 425 & 61.9 \\
\hline Disagree & 210 & 30.6 \\
\hline Agree & 44 & 6.4 \\
\hline Strongly Agree & 8 & 1.2 \\
\hline \multicolumn{3}{|c|}{ should respect men's opinions even when she does not agree } \\
\hline Strongly Disagree & 295 & 42.9 \\
\hline Disagree & 171 & 24.9 \\
\hline Agree & 194 & 28.2 \\
\hline Strongly Agree & 27 & 3.9 \\
\hline \multicolumn{3}{|c|}{ should avoid saying no to people } \\
\hline Strongly Disagree & 395 & 57.5 \\
\hline Disagree & 258 & 37.6 \\
\hline Agree & 30 & 4.4 \\
\hline Strongly Agree & 4 & 0.6 \\
\hline
\end{tabular}


Table 24 (Continued)

Marianismo Beliefs

\begin{tabular}{|c|c|c|}
\hline A Latina... & Frequency & Percent \\
\hline \multicolumn{3}{|c|}{ should do anything a male in the family asks her to do } \\
\hline Strongly Disagree & 464 & 67.5 \\
\hline Disagree & 186 & 27.1 \\
\hline Agree & 32 & 4.7 \\
\hline Strongly Agree & 5 & 0.7 \\
\hline \multicolumn{3}{|c|}{ should not discuss birth control } \\
\hline Strongly Disagree & 457 & 66.5 \\
\hline Disagree & 200 & 29.1 \\
\hline Agree & 23 & 3.3 \\
\hline Strongly Agree & 7 & 1.0 \\
\hline \multicolumn{3}{|c|}{ should not express her needs to her partner } \\
\hline Strongly Disagree & 517 & 75.3 \\
\hline Disagree & 140 & 20.4 \\
\hline Agree & 19 & 2.8 \\
\hline Strongly Agree & 11 & 1.6 \\
\hline \multicolumn{3}{|c|}{ should feel guilty about telling people what she needs } \\
\hline Strongly Disagree & 505 & 73.5 \\
\hline Disagree & 159 & 23.1 \\
\hline Agree & 17 & 2.5 \\
\hline Strongly Agree & 6 & 0.9 \\
\hline \multicolumn{3}{|c|}{ should not talk about sex } \\
\hline Strongly Disagree & 452 & 65.8 \\
\hline Disagree & 209 & 30.4 \\
\hline Agree & 21 & 3.1 \\
\hline Strongly Agree & 5 & 0.7 \\
\hline \multicolumn{3}{|c|}{ should be forgiving in all aspects } \\
\hline Strongly Disagree & 259 & 37.7 \\
\hline Disagree & 251 & 36.5 \\
\hline Agree & 148 & 21.5 \\
\hline Strongly Agree & 29 & 4.2 \\
\hline \multicolumn{3}{|c|}{ should always be agreeable to men's decisions } \\
\hline Strongly Disagree & 433 & 63.0 \\
\hline Disagree & 221 & 32.2 \\
\hline Agree & 30 & 4.4 \\
\hline Strongly Agree & 3 & 0.4 \\
\hline
\end{tabular}




\begin{tabular}{lcc} 
Table 24 (Continued) & & \\
Marianismo Beliefs & & \\
\hline A Latina... & Frequency & Percent \\
\hline should be the spiritual leader of the family & & \\
Strongly Disagree & 130 & 18.9 \\
Disagree & 218 & 31.7 \\
Agree & 300 & 43.7 \\
Strongly Agree & 39 & 5.7 \\
is responsible for taking family to religious services & & \\
Strongly Disagree & 185 & 26.9 \\
Disagree & 298 & 43.4 \\
Agree & 177 & 25.8 \\
Strongly Agree & 27 & 3.9 \\
is responsible for the spiritual growth of the family & & \\
Strongly Disagree & 148 & 21.5 \\
Disagree & 260 & 37.8 \\
Agree & 245 & 35.7 \\
Strongly Agree & 34 & 4.9 \\
\hline
\end{tabular}


Table 25

Conflict Tactics Scale 2 (Participant's Use of Psychological Aggression toward Boyfriend)

\begin{tabular}{|c|c|c|}
\hline & Frequency & Percent \\
\hline \multicolumn{3}{|l|}{ I insulted or swore at my boyfriend } \\
\hline Once that year & 54 & 7.9 \\
\hline Twice that year & 78 & 11.4 \\
\hline $3-5$ times that year & 84 & 12.2 \\
\hline $6-10$ times that year & 60 & 8.7 \\
\hline $11-20$ times that year & 39 & 5.7 \\
\hline More than 20 times that year & 47 & 6.8 \\
\hline This did not happen during that year & 325 & 47.3 \\
\hline \multicolumn{3}{|l|}{ I shouted or yelled at my boyfriend } \\
\hline Once that year & 38 & 5.5 \\
\hline Twice that year & 70 & 10.2 \\
\hline $3-5$ times that year & 86 & 12.5 \\
\hline $6-10$ times that year & 68 & 9.9 \\
\hline $11-20$ times that year & 39 & 5.7 \\
\hline More than 20 times that year & 75 & 10.9 \\
\hline This did not happen during that year & 311 & 45.3 \\
\hline \multicolumn{3}{|l|}{ I stomped out of the room } \\
\hline Once that year & 71 & 10.3 \\
\hline Twice that year & 71 & 10.3 \\
\hline 3-5 times that year & 82 & 11.9 \\
\hline $6-10$ times that year & 59 & 8.6 \\
\hline $11-20$ times that year & 19 & 2.8 \\
\hline More than 20 times that year & 28 & 4.1 \\
\hline This did not happen during that year & 357 & 52.0 \\
\hline \multicolumn{3}{|c|}{ I threatened to hit or throw something at my boyfriend } \\
\hline Once that year & 9 & 1.3 \\
\hline Twice that year & 14 & 2.0 \\
\hline 3-5 times that year & 13 & 1.9 \\
\hline $6-10$ times that year & 7 & 1.0 \\
\hline $11-20$ times that year & 6 & 0.9 \\
\hline More than 20 times that year & 5 & 0.7 \\
\hline This did not happen during that year & 633 & 92.1 \\
\hline
\end{tabular}


Table 25 (Continued)

Conflict Tactics Scale 2 (Participant's Use of Psychological Aggression toward Boyfriend)

\begin{tabular}{|c|c|c|}
\hline & Frequency & Percent \\
\hline \multicolumn{3}{|c|}{ I destroyed something belonging to my boyfriend } \\
\hline Once that year & 23 & 3.3 \\
\hline Twice that year & 4 & 0.6 \\
\hline $3-5$ times that year & 4 & 0.6 \\
\hline $6-10$ times that year & 1 & 0.1 \\
\hline $11-20$ times that year & 3 & 0.4 \\
\hline More than 20 times that year & 1 & 0.1 \\
\hline This did not happen during that year & 651 & 94.8 \\
\hline \multicolumn{3}{|l|}{ I did something to spite my boyfriend } \\
\hline Once that year & 68 & 9.9 \\
\hline Twice that year & 46 & 6.7 \\
\hline $3-5$ times that year & 41 & 6.0 \\
\hline $6-10$ times that year & 17 & 2.5 \\
\hline 11-20 times that year & 4 & 0.6 \\
\hline More than 20 times that year & 6 & 0.9 \\
\hline This did not happen during that year & 505 & 73.5 \\
\hline \multicolumn{3}{|l|}{ I called my boyfriend fat or ugly } \\
\hline Once that year & 16 & 2.3 \\
\hline Twice that year & 13 & 1.9 \\
\hline 3-5 times that year & 13 & 1.9 \\
\hline $6-10$ times that year & 3 & 0.4 \\
\hline 11-20 times that year & 3 & 0.4 \\
\hline More than 20 times that year & 4 & 0.6 \\
\hline This did not happen during that year & 635 & 92.4 \\
\hline \multicolumn{3}{|c|}{ I accused my boyfriend of being a lousy lover } \\
\hline Once that year & 43 & 6.3 \\
\hline Twice that year & 32 & 4.7 \\
\hline $3-5$ times that year & 30 & 4.4 \\
\hline $6-10$ times that year & 15 & 2.2 \\
\hline 11-20 times that year & 4 & 0.6 \\
\hline More than 20 times that year & 7 & 1.0 \\
\hline This did not happen during that year & 556 & 80.9 \\
\hline
\end{tabular}


Figure 1

Study 1 Results

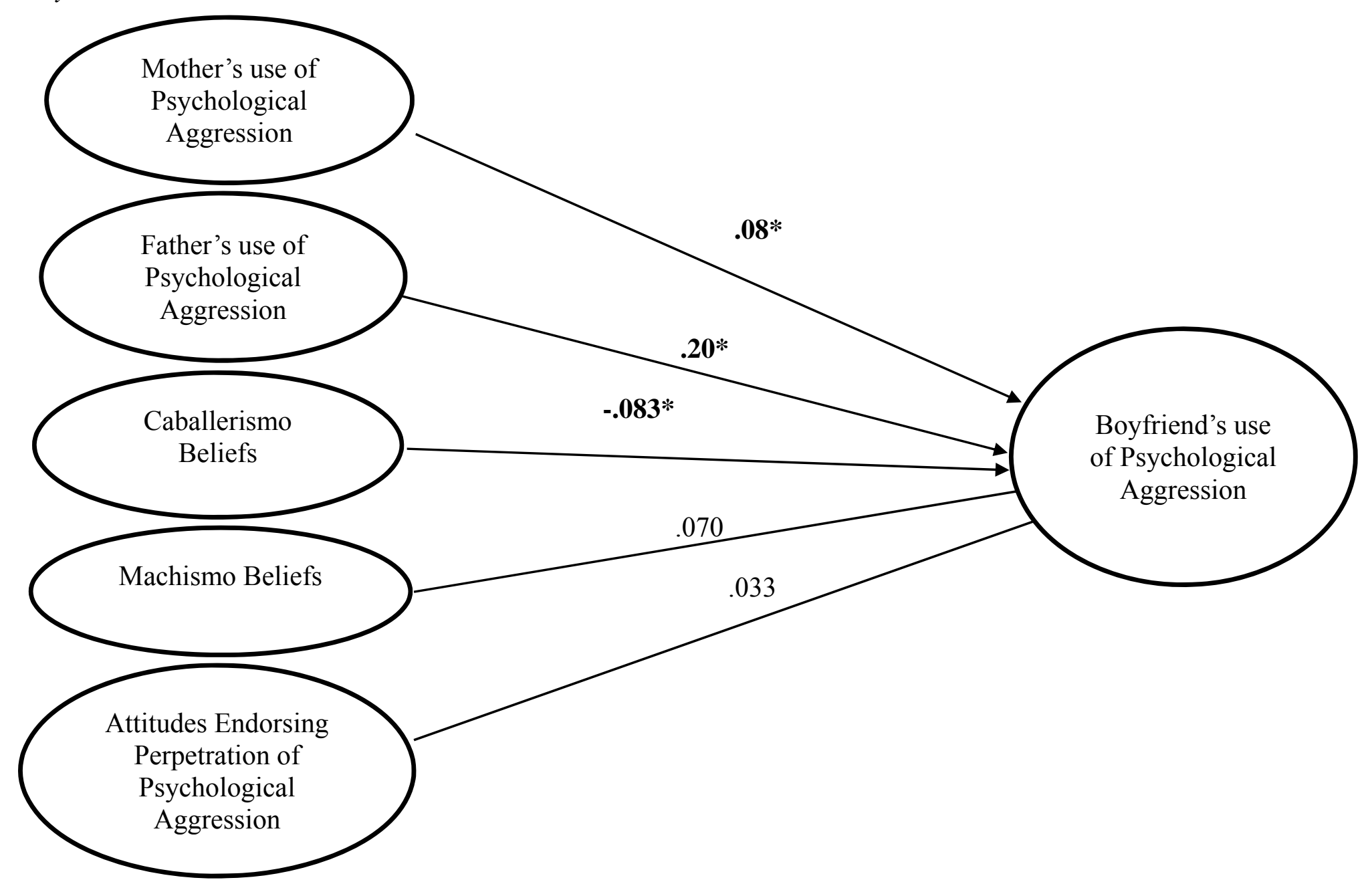


Figure 2

\section{Study 2 Results}

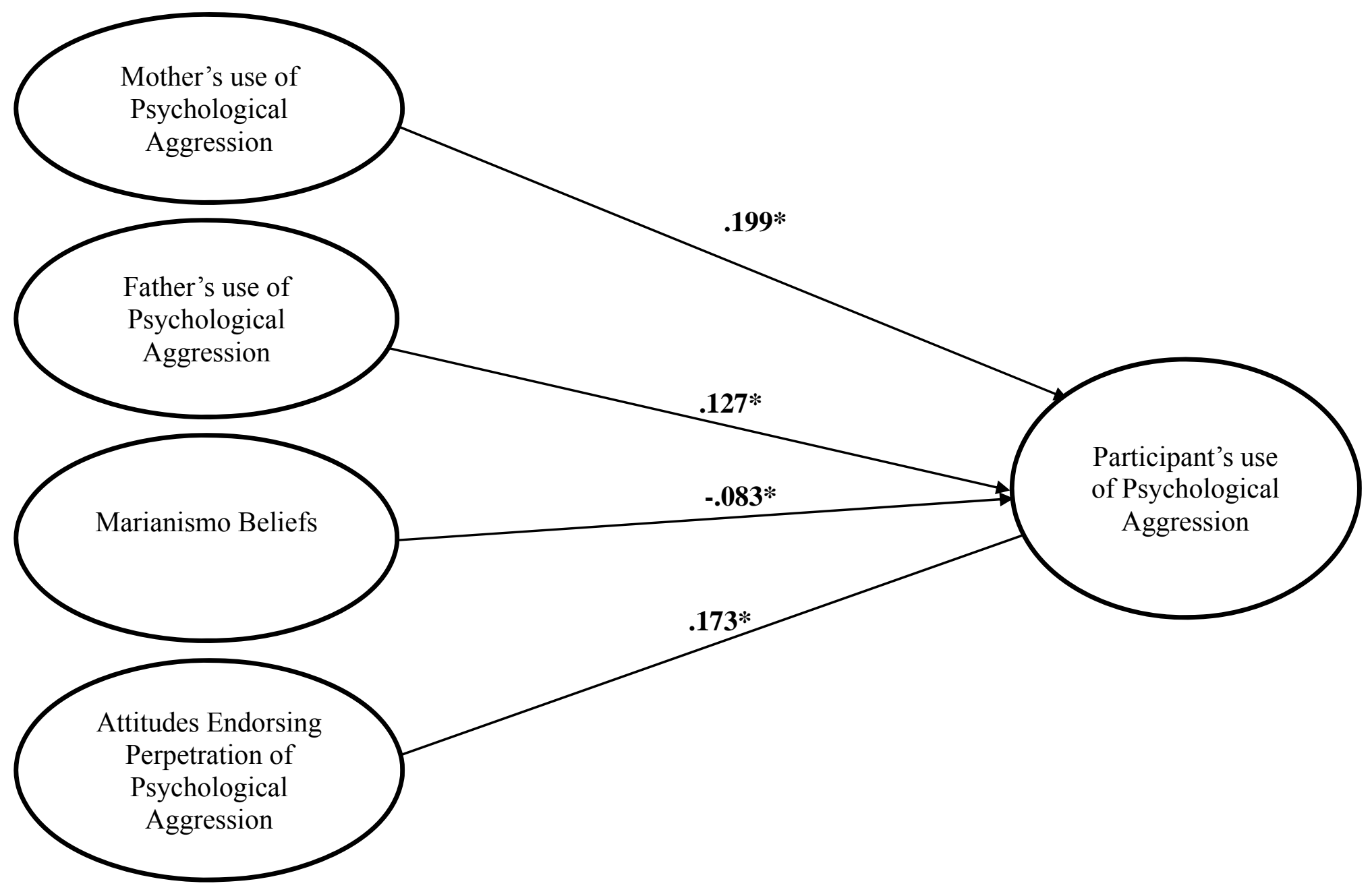


VITA

\section{LAURA A. ORAMAS}

2006-2009

B.S., Psychology with Honors

Florida International University

Miami, FL.

2009-2012

M.S., Psychology

Florida International University

Miami, FL.

2013-2014

Graduate Certificate, Women's and Gender Studies

Florida International University

Miami, FL.

$2012-2015$

Doctoral Candidate, Psychology

Florida International University, Miami, FL.

\section{PUBLICATIONS AND PRESENTATIONS}

Oramas, L. A., Stephens, D. P., \& Whiddon, M. (in press). The influence of parental conflict resolution strategies on Hispanic college women's experiences with verbal aggression. Journal of Interpersonal Violence.

Oramas, L. A. \& Quintana, S. (2013, November). Maternal Influence on Hispanic College Women's Perpetration of Physical Intimate Partner Violence. Poster session presented for the Society for the Study of Human Development, Fort Lauderdale, FL

Quintana, S. \& Oramas, L. A. (2013, November). Hispanic College Females Perpetration of Verbal Intimate Partner Violence: The Role of Maternal Modeling. Poster session presented for the Society for the Study of Human Development, Fort Lauderdale, FL.

Oramas, L. A. (2013, July). The Influence of Parental Verbal Aggression on Hispanic College Women's Intimate Relationships. Poster session presented for the American Psychological Association, Honolulu, HI.

Oramas, L. A. (2013, March). The Influence of Mothers on Hispanic College Men's Perpetration of Physical Abuse in Intimate Relationships Panel presentation of research presented in A. Eaton (Chair), Intimate relationship behaviors among minority populations: The role of culture and identity in relationship initiation, commitment, and distress for the Women, Sexuality, \& Gender Student Association Conference at Florida International University, Miami, FL. 
Oramas, L. A. (2012, August). The Influence of Parental Verbal Aggression on Hispanic College Women's Use of Aggression for the American Psychological. Roundtable paper presented in A. Eaton (Chair), Association Antecedents and Consequences of Verbal Coercion and Aggression in Young Adults’ Dating Relationships, Orlando, FL.

Oramas, L. A. (2012, August). Mothers’ Influence on Hispanic College Men's Perpetration of Physical Abuse in Intimate Relationships. Poster session presented for the American Psychological Association, Orlando, FL.

Oramas, L. A. (2012). The influence of parental verbal aggression on Hispanic college women's use of verbal aggression in romantic relationships. FIU Electronic Theses and Dissertations, paper 566: http://digitalcommons.fiu.edu/etd/566.

Oramas, L. A., Whiddon, M. A., \& Montgomery, M. J. (2009). Parent response type affects psychological adjustment in children. Psi Chi Journal of Undergraduate Research, 14, 158-165.

Oramas, L. A. (2008, October). Parent Responsiveness to Child Bids during Parent-Child Interaction and Child Psychological Adjustment. Poster session presented for the McNair Research Symposium at Florida International University, Miami, FL.

Oramas, L. A. (2008, October). Parent Responsiveness to Child Bids during Parent-Child Interaction and Child Psychological Adjustment. Presentation of research for the McNair Research Symposium, Miami, FL. 